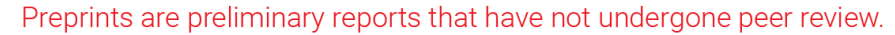 They should not be considered conclusive, used to inform clinical practice, or referenced by the media as validated information. \\ Satellite observations indicate increasing proportion of population exposed to floods
}

\section{Beth Tellman ( $\nabla$ et2663@columbia.edu )}

Columbia University, Earth Institute https://orcid.org/0000-0003-3026-6435

\section{Jonathan Sullivan}

University of Michigan https://orcid.org/0000-0001-7414-6094

\section{Catherine Kuhn}

University of Washington https://orcid.org/0000-0002-9220-630X

\section{Albert Kettner \\ Dartmouth Flood Observatory, INSTAAR, University of Colorado \\ Colin Doyle \\ University of Texas at Austin, Department of Geography \& the Environment}

\section{G. Brakenridge}

University of Colorado

Tyler Erikson

Google, Inc., Mountainview, CA

\section{Dan Slayback}

NASA Goddard Space Flight Center, Sciences and Exploration Directorate

\section{Research Article}

Keywords: floods, satellite, environmental hazard

Posted Date: September 11th, 2020

DOI: https://doi.org/10.21203/rs.3.rs-65906/v1

License: (c) (i) This work is licensed under a Creative Commons Attribution 4.0 International License. Read Full License

Version of Record: A version of this preprint was published at Nature on August 4th, 2021. See the published version at https://doi.org/10.1038/s41586-021-03695-w. 


\title{
Satellite observations indicate increasing proportion of population exposed to floods
}

Authors: B. Tellman ${ }^{*+1,2}$, J.A. Sullivan*2,3 ${ }^{*}$ C. Kuhn ${ }^{6}$, A.J. Kettner ${ }^{5}$, C.S Doyle ${ }^{2,4}$, G.R. Brakenridge $^{5}$, T. Erickson ${ }^{7}$, D.A. Slayback ${ }^{8}$

\author{
Affiliations: \\ ${ }^{1}$ Columbia Earth Institute \\ ${ }^{2}$ Cloud to Street \\ ${ }^{3}$ University of Michigan, School for the Environment and Sustainability \\ ${ }^{4}$ University of Texas at Austin, Department of Geography \& the Environment \\ ${ }^{5}$ Dartmouth Flood Observatory, INSTAAR, University of Colorado, Boulder CO \\ ${ }^{6}$ University of Washington, School of Environmental and Forest Sciences \\ ${ }^{7}$ Google, Inc., Mountainview, CA \\ ${ }^{8}$ NASA Goddard Space Flight Center, Sciences and Exploration Directorate \\ *Equal first authors \\ +Correspondence to: beth@cloudtostreet.info
}

\section{Bold first paragraph:}

Flooding affects more people than any other environmental hazard and hinders sustainable development ${ }^{1-3}$. Investing in flood adaptation can reduce loss of life and livelihoods 4,5 . However, where and how floods occur, and who is exposed, is changing due to rapid urbanization $^{6}$, new flood mitigation infrastructure ${ }^{7,8}$, and increasing human settlements in floodplains ${ }^{9}$. Previous studies estimating population exposed to floods are limited by lack of observational data, relying instead on global models with high uncertainty ${ }^{4,10-14}$. Here we use nearly two decades of daily satellite imagery at 250 meter resolution (MODIS) to develop new estimates of flood extent and population exposure for 913 large flood events from 2000-2018, estimating 2.23 million $\mathrm{km}^{2}$ of flooded area and 290 million people directly affected. We find the at least 86 million people newly settled in a location where satellites observed inundation in the past 20 years. This represents a $20 \%$ increase in the proportion of population exposed to floods, ten times higher than previous estimates ${ }^{10}$. Near-future climate change projections (2030), indicate the proportion of population exposed to floods will continue to expand. Our findings can aid prioritization of global flood adaptation investment and inform adaptation strategies, from insurance to managed retreat, at local scales ${ }^{15-17}$. As satellite coverage and resolution increase, we anticipate observation of flood events to aid understanding where floods change and how to adapt. This flood event database will contribute to improved accuracy of global and local flood models, vulnerability assessments, efficacy of adaptation intervention, and understanding interactions of land change, climate, and floods. 
Damaging floods are increasing in severity, duration, and frequency due to climate, land use, infrastructure, and demographic changes ${ }^{10,18-21}$. From 2000-2017 there were an estimated $\$ 18$-billion in annual flood damages globally ${ }^{3}$. Investments in flood adaptation have reduced mortality and asset losses ${ }^{4,22}$. Yet, only $13 \%$ of all disaster funds are allocated towards disaster preparedness, mitigation, and adaptation ${ }^{23}$. Improved estimates of flood exposure are needed to prioritize disaster mitigation efforts.

Studies examining changes to flood exposure, vulnerability, and the relative role of socioeconomic and climate change, rely on modeled flood hazard ${ }^{10,11,13,19,24,25}$. One study estimates population growth in 100-year floodplains has outpaced total population by 2.6 percent from 1970-2010 in 22 countries $^{10}$. Flood vulnerability, measured as the relative loss of life and property, controlling for hazard size, has decreased since the $1950 \mathrm{~s}^{4,13,14}$. Sub-Saharan Africa is the only region with increasing vulnerability, with increased flood mortality rates since $1990^{13,26}$.

The accuracy of modeled global flood exposure is limited by the difficulty of incorporating rapid anthropogenic and environmental changes, flood defenses, inadequate calibration data, and poor quality topographic data ${ }^{27}$. Changes in land use, demographics, and infrastructure dynamically reshape flood exposure as human modifications to rivers (e.g. dam construction, paving floodplains, and channelizing) mitigate, exacerbate, or shift flood waters $7,8,28$. Global hazard models differ in their structure and assumptions, leading to high disagreement of population and area exposure estimates ${ }^{12,27}$.

Contrary to models, remote sensing methods based on satellite data can directly estimate inundated extent through time ${ }^{29-33}$. Observing inundation where and when it occurs implicitly accounts for changes in climate, land use, and infrastructure not reflected in modeled flood extents. However, no remote sensing studies provide continental or global observations of flood extent needed to prioritize adaptation internationally.

To address this need, we developed a novel Global Flood Database (GFD) using satellite observations of 913 large flood events documented by the Dartmouth Flood Observatory (DFO) from 2000-2018 at 250m resolution. We provide the first attempt, to our knowledge, of using MODIS or any satellites to systematically map maximum observed surface water extent during flood events from event catalogues at global scales. Our database aggregates maximum inundated extent across discrete flood events, differing from extant continuous time series surface water products available in monthly aggregations at $30-\mathrm{m}$ resolution ${ }^{34}$ or daily observations at 500-m resolution ${ }^{35,36}$ which do not explicitly target flood events. The Global Flood Database complements existing water datasets by providing a geospatial catalog of flood events to enable flood model calibration and intercomparison ${ }^{37}$.

We estimate flood population exposure by intersecting maximum inundation extent with the Global Human Settlement Layer (GHSL) ${ }^{38}$. The change in flood exposure is measured by comparing the proportion of the population exposed to floods in 2015 versus 2000 for each country (Eq. 7, methods). This method is similar to that used in a previous study ${ }^{10}$ and determines where flood exposure changes were relatively larger or smaller than population changes.

In addition to identifying countries with flood exposure in the recent past (2000-2015), we estimated the flood exposure change for the near future (2010-2030) using flood hazard extents from "GLObal Flood Risk with IMAGE Scenarios" (GLOFRIS) based on present day emissions scenarios ${ }^{39}$ and socioeconomic trends ${ }^{40}$ for large events (the 100 -year return period). We compare observations of flood exposure change in the recent past to modeled estimates of the near future, to identify countries on slowing, continuing, or increasing flood-exposed 
development trajectories. This analysis can enable prioritization of flood adaptation measures for regions where flood exposure has been growing or may grow faster than total population under a changing climate.

\section{Satellite Observed Inundation}

We analyze 12,719 NASA MODIS images from 2000-2018 to produce 913 flood maps (Fig. 1A, and Extended Data Fig. 1). We detected surface water at 250-m resolution via a remote sensing algorithm applying empirically derived thresholds for short-wave infrared (band 7), nearinfrared (band 2) and red (band 1) wavelengths from MODIS, an orbiting optical satellite that images the entire earth twice daily ${ }^{41,42}$. We modify this algorithm by using adaptive Otsu thresholds ${ }^{43}$ to account for varying global and seasonal flood conditions in coastal and riverine floods (Extended Data Fig 2). Results were validated using higher spatial resolution $(30 \mathrm{~m})$ Landsat scenes coincident to maximum flood day $(\mathrm{n}=123$ events) (Extended Data Figure 3). An accuracy assessment based on 30,685 individual validation points found an overall mean accuracy of $83 \%$ (std. 15\%) for empirical thresholds and $80 \%$ (std. 12\%) for Otsu derived thresholds. Large errors of commission $(>65 \%)$ were concentrated in Northern Latitudes, likely due to low sun angle on dark soil with low reflectance being confused with water ${ }^{44}$. Errors of omission show no geographic pattern (see Extended Data Fig 4 \& 5).

Most of the 913 flood events in the Global Flood Database are in Asia (398), followed by the Americas (223), Africa (143), Europe (92), and Oceana (57). Floods spread over multiple countries give rise to 2,617 individual country events, with population and exposed area calculated for each. The countries with the highest flood event counts are China (164), India (144), Bangladesh (100) and the United States (98) (Figure 1A). 90\% of flood-exposed population is concentrated in South and Southeast Asia, also indicated by global flood models ${ }^{45}$. Over 290 million people have been exposed to at least one observed flood event since 2000 (Figure 1C), representing nearly 3\% of the world's population. The two years with the highest population exposure to floods globally were 2007 and 2010, but the two years with highest inundated area were 2003 and 2007.

Of the 3,054 events originally catalogued from news reports (with no notable increase over time due increased reporting, see Extended Data Fig 8A), 913 events had enough highquality satellite imagery available for flood exposure analyses. Flood extent for the remaining 2,141 could not be mapped due to persistent cloud cover and floods that were too small, too quick (flash floods) or in too complex of terrain (e.g. dense forest or urban areas) to be detected with MODIS (Extended Data Fig 6). Large floods in unpopulated areas may not be recorded in the DFO event catalogue, and some event maps underrepresent maximum flood extent due to aforementioned uncertainty. Nonetheless, many notable flood events extents mapped were associated with high socioeconomic losses (Figure 2A-D). 
A

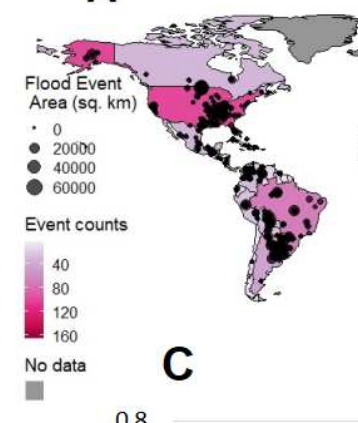

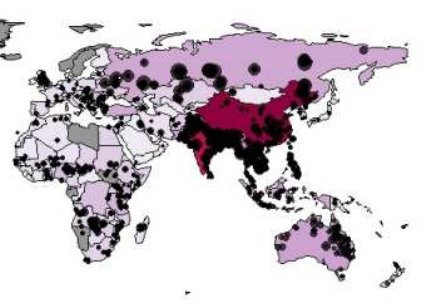

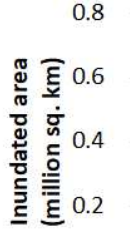

0
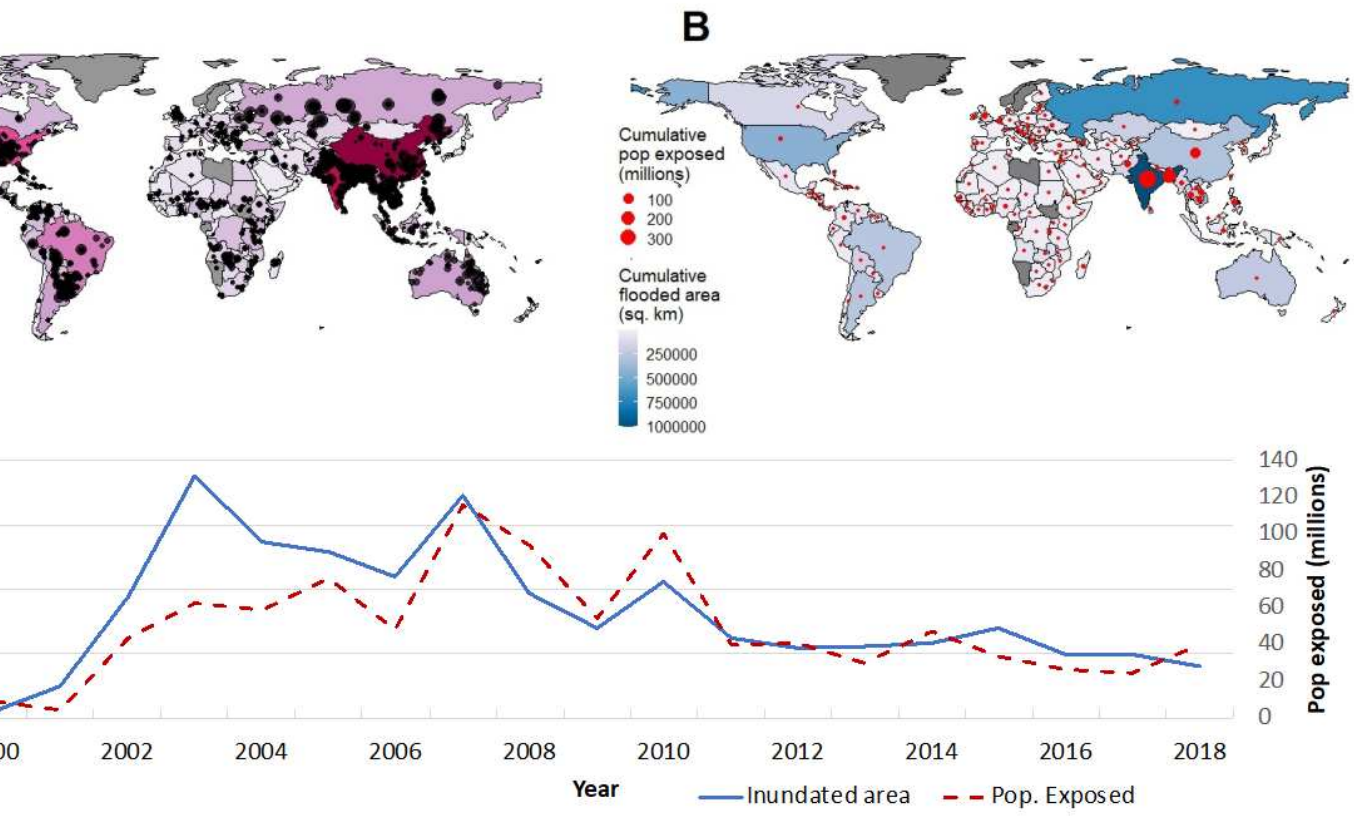

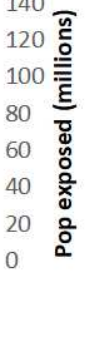

Figure 1. Summary Statistics of the Global Flood Database. A) Number of events in the Global Flood Database per country, with centroid locations marked in black B) Map of total exposed population and exposed area (per country, Supplementary Table 6) and C) Annual global population and area inundated. The 913 flood events only represent those for which high quality data was available (see quality control section, methods). Population and area exposure to floods are lower in 2000 and 2001 until a second satellite (Aqua) was launched with a MODIS sensor on board, allowing for twice daily global coverage and increasing the probability of mapping a flood event from 5\% in 2000 to $30 \%$ in 2002 and afterwards. 


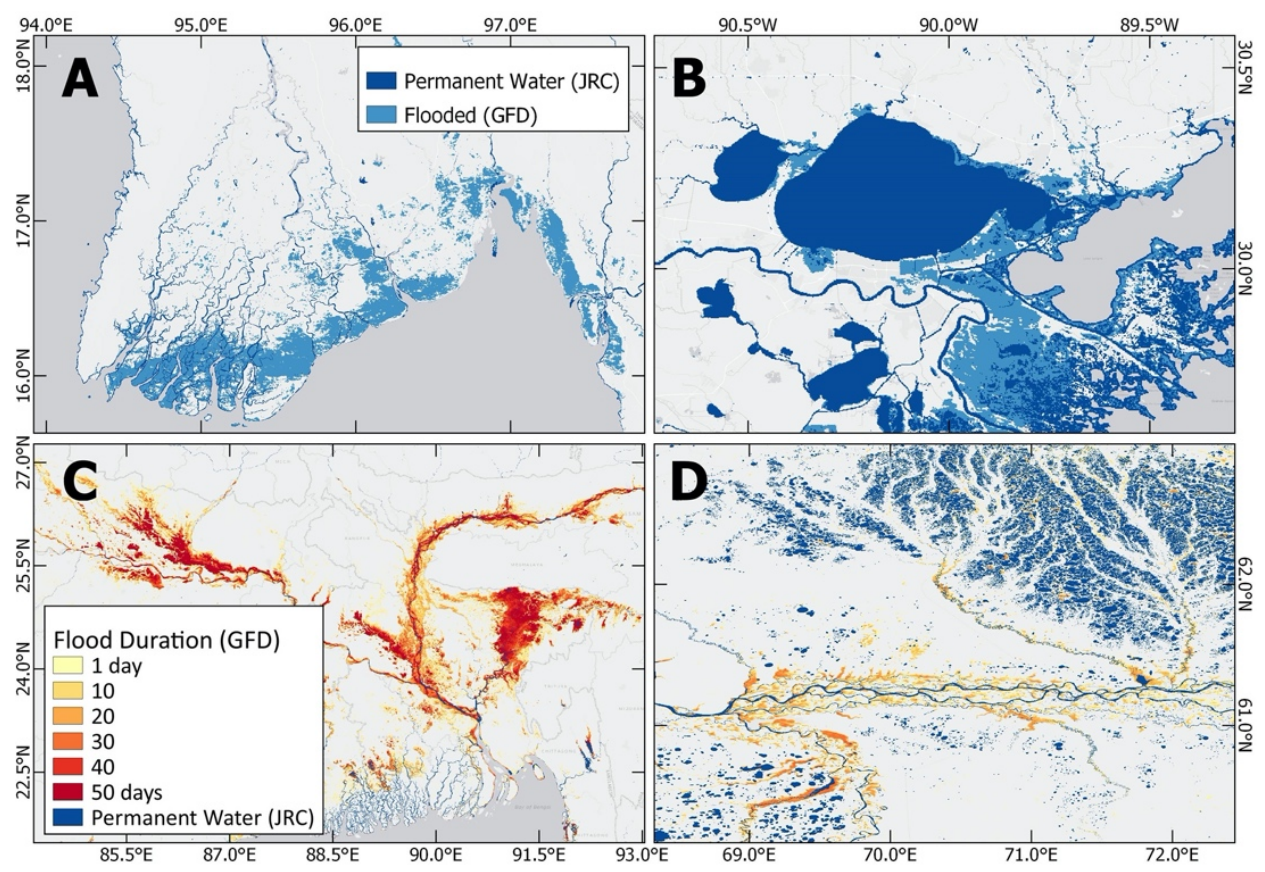

Figure 2. Observed inundation in the Global Flood Database versus permanent water (from the Joint Research Program (JRC), see Pekel et al 2016) (A-B) and flood duration versus permanent water (C-D) for selected extreme flood events of the Global Flood Database. A) The highest mortality; 100,000 people due to Cyclone Nargis, Burma, 2008. B) The most expensive event; Hurricane Katrina, 60 billion USD, 2005. C) The highest estimated exposure, 27 million people, exposed to the 2004 floods in India and Bangladesh. D) The largest flood (98,000 $\mathrm{km}^{2}$ ), observed in Russia, 2003. (Basemap: Bing Maps).

\section{Past proportion of population exposed to large floods: 2000-2015}

Global absolute population growth from 2000-2015 increased only $18.6 \%$, compared to $34.1 \%$ in areas of observed inundation. Between 2000-2015, 86 million people, or 30\% of the total population exposed, were newly residing in areas where inundation was observed at least once in the Global Flood Database record. Using the maximum spatial extent of observed inundation, we estimate the change in the proportion of the population exposed to floods was 1.20, averaged across all countries (see methods Eq. 7). This represents a $20 \%$ mean increase in the proportion of the population exposed to large flood events from 2000 ( $\mathrm{std}=+/-53 \%)$; this mainly occurred in low- and middle-income countries (Figure 4A).

The proportion of population in inundated areas increased from 2000-2015 (>1.02) in 78 countries. In 41 of these countries, the proportion of population exposed to floods is $>1.2$ (the $75^{\text {th }}$ percentile of all values). Examples of locations with large population growth in observed inundation areas include Guwahati, India where urbanization along large rivers rapidly increased flood exposure and Dhaka, Bangladesh (see figure 3C and 3D). Countries and regions where the proportion of population exposed to floods has grown include Asia (Myanmar, Thailand, Pakistan, and Nepal) and Sub-Saharan Africa (Burkina Faso, Botswana, Ghana, Ivory Coast, Nigeria, Niger, Benin, Zimbabwe, Madagascar, Malawi, and Mozambique). Recent rapid urban growth $^{6}$ and informal urbanization in particular (urban growth outside planned areas) in floodplains could explain the increasing trends in these regions ${ }^{26,46}$. For the Americas, in several 
countries (Argentina, Ecuador, Guatemala, Cuba, and Paraguay), the proportion of population exposed to floods is high in historically inundated areas.

In 22 countries there is little to no change in the proportion of population exposed to floods $(>0.97$ and $<1.02)$. Many of these are in Northern and Southern Europe, in regions where populations have declined in, for example, Eastern Europe and Russia ${ }^{47}$. Scale matters; some specific cities may have unchanged flood exposure that buck regional trends. For example, Manaus, Brazil (Figure 3B) has not experienced population growth in areas of observed inundation. However, Brazil overall is increasing its proportion of population exposed to floods.

In 38 countries, the proportion of population exposed to floods decreased $(<0.97)$. Populations have decreased in regions of flood exposure in the USA, such as New Orleans, USA, after Hurricane Katrina (see Figure 3A), consistent with other studies showing decreases in urbanization and population exposure in modeled FEMA flood zones in the coastal US ${ }^{48,49}$. In Sri Lanka, a decrease in the proportion of population exposed to floods is partially due to policy changes after the 2004 tsunami requiring residents to relocate at least $100 \mathrm{~m}$ from the shoreline, which displaced up to 500,000 people ${ }^{50,51}$.
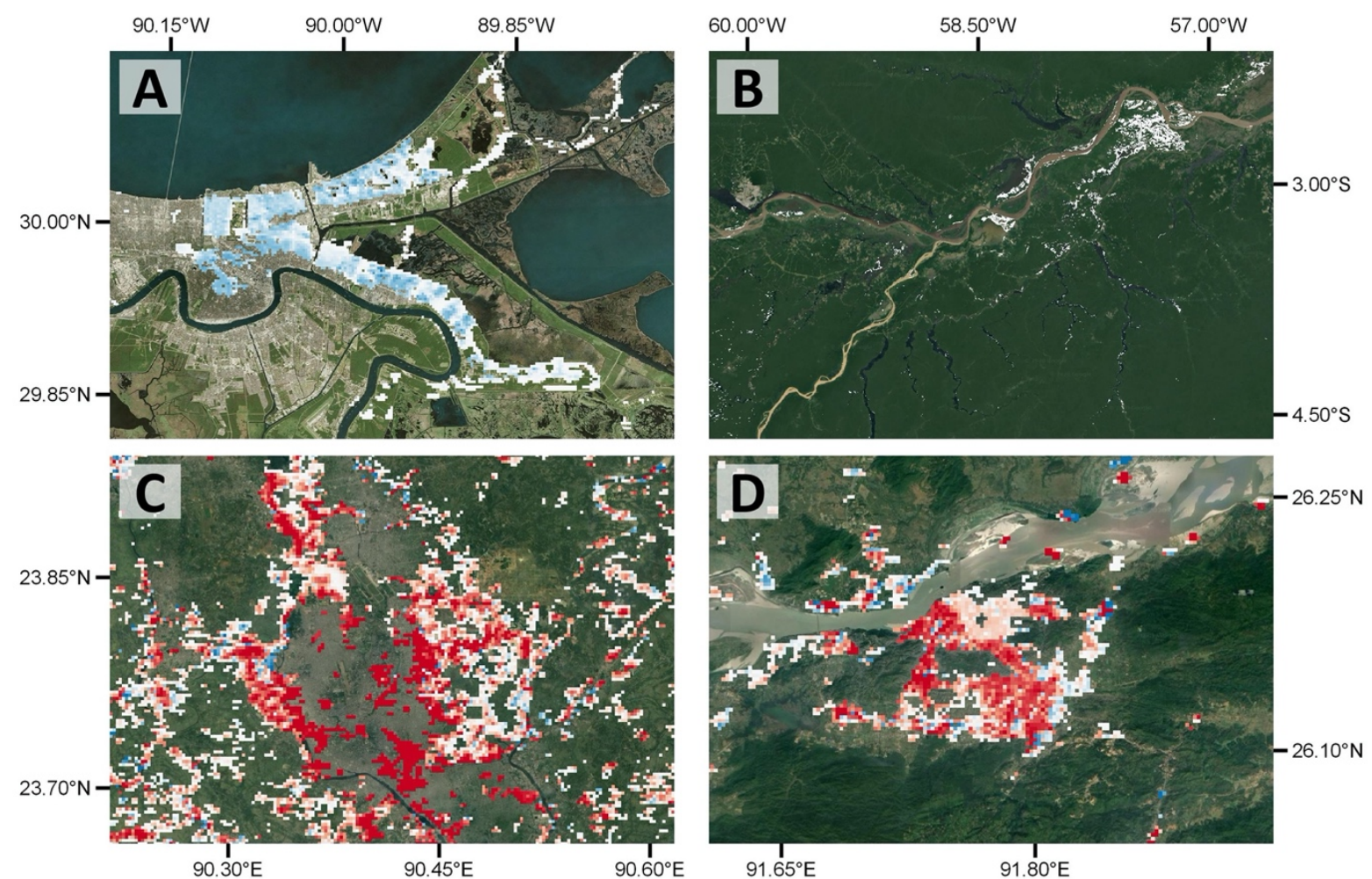

Population $\Delta$ (persons)

$-500$ $-375$ $-100$ $-50 \square 0 \square 50 \square 100$ $250 \square 50$

Figure 3. Population dynamics per pixel $(250 \mathrm{~m})$ in observed inundated areas, 2000-2018. A) New Orleans, Louisiana, loses population after Hurricane Katrina (Basemap: Bing Maps). B) Manaus, Brazil, no population change C) Dhaka, Bangladesh, increasing population in inundated areas in the peri-urban zone. D) Guwahati, Assam, India, an urbanizing town on the Brahmaputra River repeatedly exposed to flooding over the past two decades. (Basemap B-D: Google Maps) 


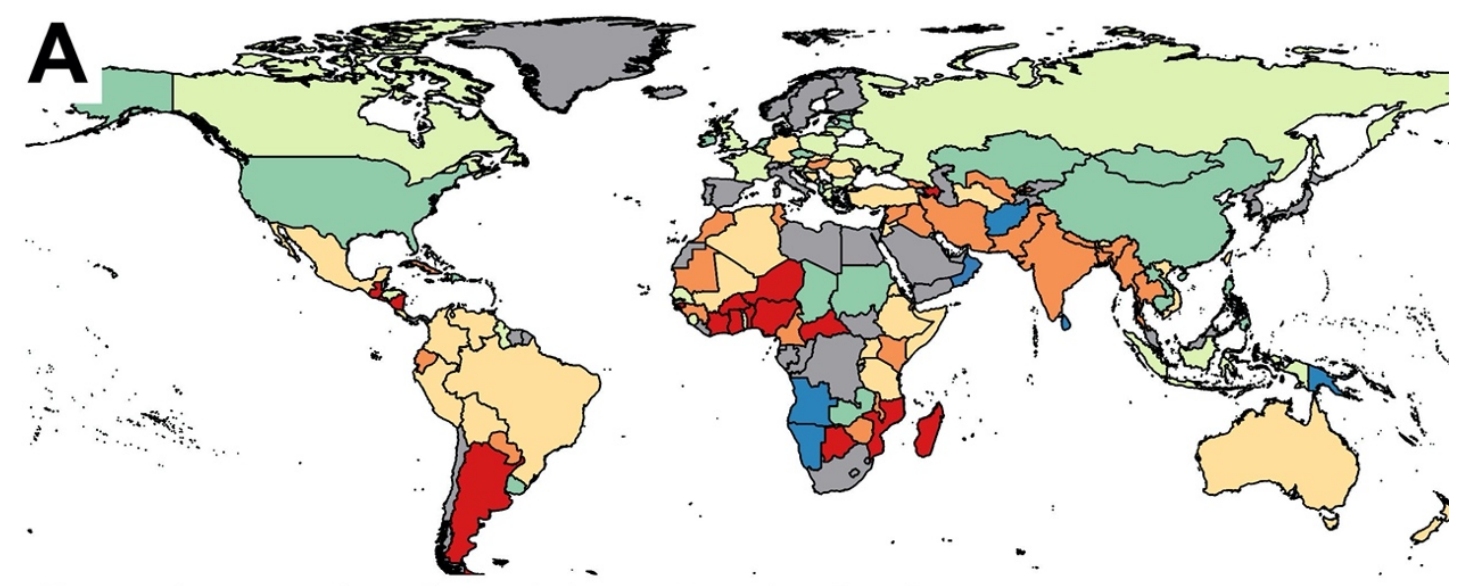

Change in proportion of population exposed to floods

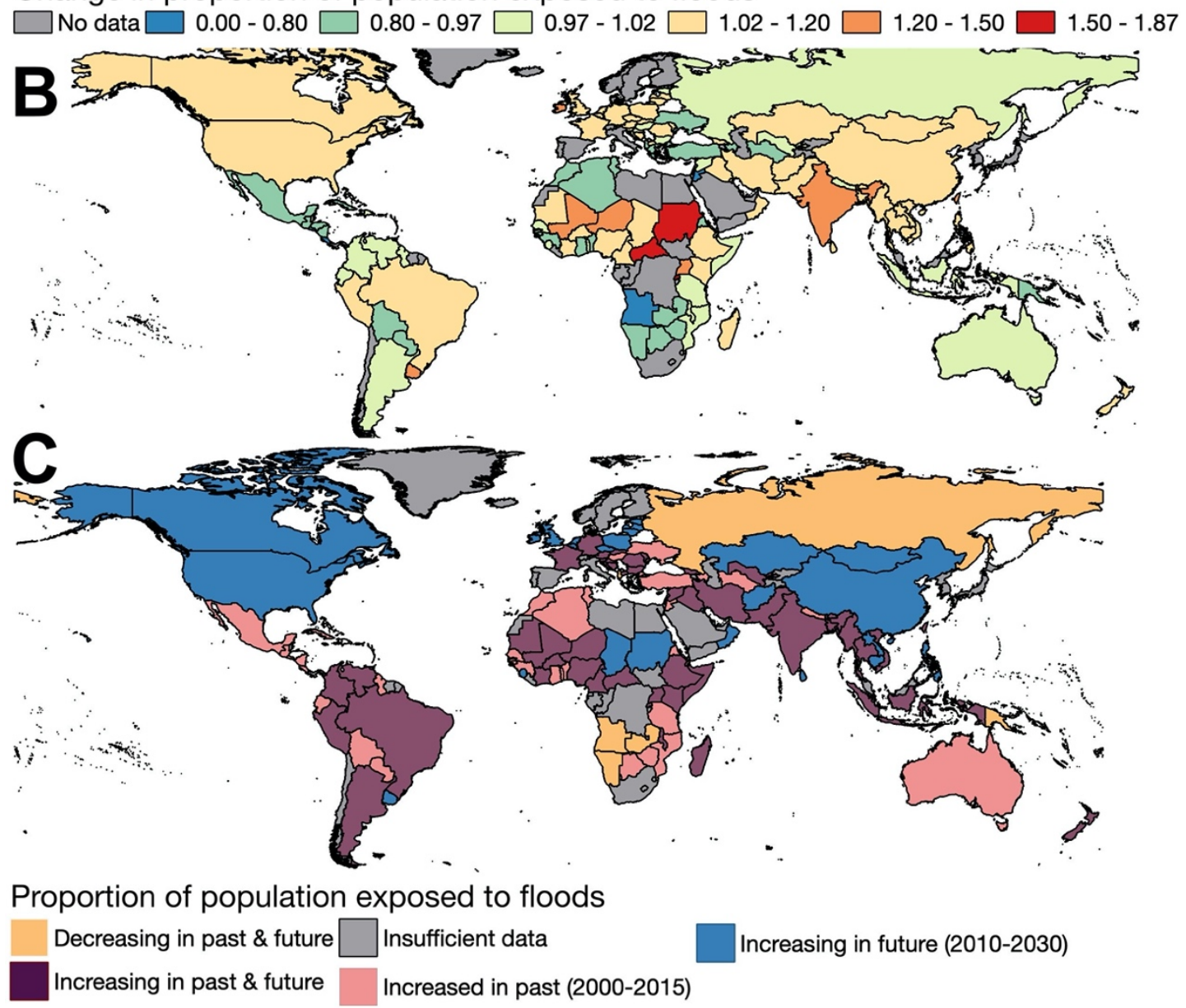

Figure 4. Change in proportion of population exposed to floods observed from satellites and predicted for $\mathbf{2 0 3 0}$ from a flood model. (A) Change in proportion of population exposed to floods in observed inundated areas per country, 2000-2015 (B) Change in proportion of floodexposed population relative to rates of total population change per country, 2010-2030. Color breaks match classification from Jongman et al. (2012) to facilitate comparison. C) Countries where the proportion of population exposed to large floods grew (2000-2015) (>1, pink), is expected to grow (2010-2030) (>1, blue), has increased in both the past and future (purple), and remains constant or is decreasing (orange). Grey countries had insufficient flood observations. 
We calculated population exposed to floods in the near future (2010-2030) in countries with high quality large flood event observations in the recent past and near future (WRI flood risk analyzer ${ }^{45}, \mathrm{n}=120$ countries). Across these 120 countries, Aqueduct estimates 580 million people reside in the 100-year return period flood in 2010. By 2030, $\mathrm{WRI}^{45}$ estimates up to 758 million people will reside in the 100-year flood zone with increases in flood exposure due to demographic (117 million people) and climate change (50.3 million people, based on RCP 8.5). The proportion of population exposed to flood in the near future increased globally but varied widely across countries (global mean $=1.04$, standard deviation $=0.9$ ) and was not sensitive to different return periods (see Extended Data Fig 7). Most regions are expected to increase the proportion of population exposed ${ }^{19}$ (Fig 4B). In 64 countries flood exposure is expected to outpace future population growth, with the highest ratios in Asia and Africa, as noted by previous studies ${ }^{5}$.

\section{Changes in proportion of flood exposure, past and future}

We compare the change in the proportion of the population exposed to large flood events in the recent past (2000-2015, captured by the Global Flood Database in combination with the Global Human Settlement Layer (GHSL)) to 2010-2030. We classify countries and regions as having new, slowing, continuous, or never having flood exposure change higher than population growth. New signifies countries where the proportion of population exposed to floods is increasing only in the near future; slowing for countries where flood exposure increased in the recent past and will decrease in the near future; continuous for countries where flood exposure increased in the recent past and will in the near future; and never for regions where flood exposure did not increase in the past nor is it expected to in the future.

Most regions (9) and countries (40) are classified as continuous, and are spread across 4 continents (Figure 4C, Supplementary Information Table 4 and 5 for a list of countries and regions). Seven countries exhibit exceptionally high continuing increased flood exposure change $(>1.2)$ including India and six African countries. Many new regions (5) and countries (29) will experience increased flood exposure in the future in contrast to the recent past, and are concentrated in Europe, North America, and East Asia. Countries with new increasing flood exposure changes higher than 50\% include Oman, Sri Lanka, and Sudan. These may be the countries most unprepared or "surprised" by extreme flood events.

The proportion of population exposed to flood is slowing in 5 regions and 21 countries. Yet even in these regions, an estimated 2.2 million additional people will be exposed to 100 -year return period floods by 2030 according to modeled estimates. The change in proportion of population exposed to flood is low in part because total population growth is so high. Flood exposure does not outpace population growth in one region (Melanesia) and 10 never countries.

\section{Discussion}

Our results provide new evidence from satellite observations that changes in flood exposure are higher and more globally widespread than previously thought. We find the proportion of population exposed to large floods has increased by $20 \%$ from $2000-2015$, significantly higher than the previously reported $2.6 \%$ in a study examining trends from 1970 $2010^{10}$. We find widespread increases in the proportion of population exposed to floods for 78 
countries, across all continents, in contrast to previous studies reporting 22 or 55 countries, concentrated in Sub-Saharan Africa and Asia ${ }^{10,13}$. Our study identifies previously unidentified areas of recent increases in flood exposure, especially in Southern Asia, Southern Latin America, and the Middle East. Our estimates may be higher than previous simulation studies because inundation observations capture events caused by flood dynamics not included in global models, such as dam breaks, pluvial events, snowmelt, and other causes. In addition, recorded flood events in the Dartmouth Flood Observatory includes events from a wide range of return periods from frequent flood events (e.g.10-year return period), to the highest flood on record of an unknown recurrence interval (e.g., exceeding the 500-year return periods). Future work should further improve population exposure estimates by i) incorporating more flood events and using additional satellites, ii) modeling flood event extents when imagery fails to capture events (e.g in flash floods), and iii) assigning event return periods to better compare trends from observations to those predicted by hazard models.

Accelerated population growth in observed inundated areas is largely due to increased economic development and population migration into the floodplain. We are unable to differentiate between exogenous and endogenous drivers of flood exposure. For example, urbanization and human settlements near floodplains may cause endogenous feedbacks as impervious surface area grows ${ }^{52}$, further increasing inundated area. Alternatively, climatic changes could already be increasing inundation extent into existing areas of high population growth, for example, in Houston, Texas ${ }^{53}$. More frequent medium and long duration floods have occurred since 1985 in the tropics, which could be related to long term climate variability (e.g. ENSO frequency or magnitude $)^{21}$.

We identified countries with flood exposure trajectories that are continuing, slowing, or will newly undergo population expansion in flood prone areas. Countries where the proportion of population exposed to floods has grown in either the recent past (75) or is predicted to grow in the near future (65) indicates risky flood prone development patterns placing lives and livelihoods at risk. Of great concern are the 29 countries that may newly experience growing proportions of population exposed to floods. Satellite observations identify populations in areas of known inundation risk and can inform appropriate adaptation efforts, including flood protection $^{5}$ and managed retreat ${ }^{16}$ at local and regional levels ${ }^{17}$. For example, observed change in population in inundated areas aids local governance efforts to track vulnerability over time and plan flood resilient futures ${ }^{54}$. Flood observation data may inform market signals to price municipal bonds ${ }^{55}$, insurance ${ }^{15}$, and other financial instruments to plan for a changing (or already changed) tax base.

The database presented here represents a major advance in providing global spatial flood event data in an open-access catalog for public download at $250 \mathrm{~m}$ resolution, allowing users to examine exposure trends at local and regional levels. Future research can improve the multiimage thresholding algorithm used here, for example, by identifying floods for singular MODIS images, and increase the number, resolution of events by incorporating current and future sensors (e.g. Sentinel-2 (2016), Sentinel-1 (2014), SWOT (expected launch 2021), NISAR (expected launch 2022)) to improve estimates of maximum flood extent. The global flood event database can identify human settlement growth in areas of observed inundation for adaptation planning and aid flood model calibration and comparison, thereby improving understanding of global flood hazard and vulnerability. 


\section{References}

1. UNISDR. The Human Cost of Weather Related Disasters 1995-2015. (2015).

2. Hallegatte, S., Vogt-Schilb, A., Bangalore, M. \& Rozenberg, J. Unbreakable: Building the Resilience of the Poor in the Face of Natural Disasters. (The World Bank, 2016). doi:10.1596/978-1-46481003-9.

3. CRED. 2018 Review of Disaster Events. (2019).

4. Jongman, B. et al. Declining vulnerability to river floods and the global benefits of adaptation. Proc. Natl. Acad. Sci. 201414439 (2015) doi:10.1073/pnas.1414439112.

5. Jongman, B. Effective adaptation to rising flood risk. Nat. Commun. 3 (2018).

6. Liu, X. et al. High-spatiotemporal-resolution mapping of global urban change from 1985 to 2015. Nat. Sustain. (2020) doi:10.1038/s41893-020-0521-x.

7. Chin, A. Urban transformation of river landscapes in a global context. Geomorphology 79, 460-487 (2006).

8. Grill, G. et al. Mapping the world's free-flowing rivers. Nature 569, 215-221 (2019).

9. Ceola, S., Laio, F. \& Montanari, A. Satellite nighttime lights reveal increasing human exposure to floods worldwide. Geophys. Res. Lett. 7184-7190 (2014) doi:10.1002/2014GL061859.Received.

10. Jongman, B., Ward, P. J. \& Aerts, J. C. J. H. Global exposure to river and coastal flooding: Long term trends and changes. Glob. Environ. Change 22, 823-835 (2012).

11. Winsemius, H. C. et al. Global drivers of future river flood risk. Nat. Clim. Change 6, 381-385 (2015).

12. Trigg, M. A. et al. The credibility challenge for global fluvial flood risk analysis. Environ. Res. Lett. 11, 094014 (2016).

13. Tanoue, M., Hirabayashi, Y. \& Ikeuchi, H. Global-scale river flood vulnerability in the last 50 years. Sci. Rep. 6, (2016).

14. Formetta, G. \& Feyen, L. Empirical evidence of declining global vulnerability to climate-related hazards. Glob. Environ. Change 57, 101920 (2019).

15. Surminski, S. \& Oramas-Dorta, D. Flood insurance schemes and climate adaptation in developing countries. Int. J. Disaster Risk Reduct. 7, 154-164 (2014).

16. Siders, A. R., Hino, M. \& Mach, K. J. The case for strategic and managed climate retreat. Science 365, 761-763 (2019).

17. Rojas Blanco, A. V. Local initiatives and adaptation to climate change: Local Initiatives and Adaptation to Climate Change. Disasters 30, 140-147 (2006).

18. IPCC. Impacts of $1.5^{\circ} \mathrm{C}$ global warming on natural and human systems. in Global Warming of $1.5 \mathrm{C}$.

19. Ward, P. J. et al. Assessing flood risk at the global scale: Model setup, results, and sensitivity. Env. Res Lett 8, 44019 (2013).

20. Alfieri, L. et al. Global projections of river flood risk in a warmer world. Earths Future 5, 171-182 (2017).

21. Najibi, N. \& Devineni, N. Recent trends in the frequency and duration of global floods. Earth Syst. Dyn. 9, 757-783 (2018).

22. Ward, P. J. et al. A global framework for future costs and benefits of river-flood protection in urban areas. Nat. Clim. Change 7, 642-646 (2017).

23. Kellet, J. \& Caravani, A. Financing Disaster Risk Reduction: A 20 year story of international aid. (2013).

24. Yamazaki, D., Kanae, S., Kim, H. \& Oki, T. A physically based description of floodplain inundation dynamics in a global river routing model: FLOODPLAIN INUNDATION DYNAMICS. Water Resour. Res. 47, (2011).

25. Sampson, C. C. et al. A high-resolution global flood hazard model. Water Resour. Res. 51, 73587381 (2015).

26. Di Baldassarre, G. et al. Flood fatalities in Africa: From diagnosis to mitigation: FLOOD FATALITIES IN AFRICA. Geophys. Res. Lett. 37, 1-5 (2010). 
27. Ward, P. J. et al. Usefulness and limitations of global flood risk models. Nat. Clim. Change 5, 712715 (2015).

28. Shastry, A. et al. Small-scale anthropogenic changes impact floodplain hydraulics: Simulating the effects of fish canals on the Logone floodplain. J. Hydrol. 588, 125035 (2020).

29. Bates, P. D. Remote sensing and flood inundation modelling. Hydrol. Process. 18, 2593-2597 (2004).

30. Coltin, B., McMichael, S., Smith, T. \& Fong, T. Automatic boosted flood mapping from satellite data. Int. J. Remote Sens. 37, 993-1015 (2016).

31. Cian, F., Marconcini, M. \& Ceccato, P. Normalized Difference Flood Index for rapid flood mapping: Taking advantage of EO big data. Remote Sens. Environ. 209, 712-730 (2018).

32. Chini, M. et al. Sentinel-1 InSAR Coherence to Detect Floodwater in Urban Areas: Houston and Hurricane Harvey as A Test Case. Remote Sens. 11, 107 (2019).

33. DeVries, B. et al. Rapid and robust monitoring of flood events using Sentinel-1 and Landsat data on the Google Earth Engine. Remote Sens. Environ. 240, 111664 (2020).

34. Pekel, J.-F., Cottam, A., Gorelick, N. \& Belward, A. S. High-resolution mapping of global surface water and its long-term changes. Nature (2016).

35. Klein, I., Dietz, A., Gessner, U., Dech, S. \& Kuenzer, C. Results of the Global WaterPack: a novel product to assess inland water body dynamics on a daily basis. Remote Sens. Lett. 6, 78-87 (2015).

36. Ji, L., Gong, P., Wang, J., Shi, J. \& Zhu, Z. Construction of the 500-m Resolution Daily Global Surface Water Change Database (2001-2016). Water Resour. Res. 54, 10,270-10,292 (2018).

37. Bernhofen, M. V. et al. A first collective validation of global fluvial flood models for major floods in Nigeria and Mozambique. Environ. Res. Lett. 13, 104007 (2018).

38. European Commission, Joint Research Centre \& Columbia University, Center for International Earth Science Information Network. GHS population grid, derived from GPW4, multitemporal (1975, 1990, 2000, 2015). (2015).

39. Riahi, K. et al. RCP 8.5-A scenario of comparatively high greenhouse gas emissions. Clim. Change 109, 33-57 (2011).

40. Riahi, K. et al. The Shared Socioeconomic Pathways and their energy, land use, and greenhouse gas emissions implications: An overview. Glob. Environ. Change 42, 153-168 (2017).

41. Brakenridge, R. \& Anderson, E. MODIS-based flood detection, mapping and measurement: The potential for operational hydrological applications. in Transboundary floods: reducing risks through flood management 1-12 (Springer, 2006).

42. Policelli, F. et al. The NASA Global Flood Mapping System. Remote Sens. Hydrol. Extrem. 47 (2016).

43. Otsu, N. A threshold selection method from gray-level histograms. Automatica 11, 23-27 (1975).

44. Nigro, J., Slayback, D., Policelli, F. \& Brakenridge, G. R. NASA/DFO MODIS near real-time (NRT) global flood mapping product evaluation of flood and permanent water detection. (2014).

45. World Resources Institute. Aqueduct Global Flood Risk Maps. (2015).

46. Salami, R. O., von Meding, J. K. \& Giggins, H. Urban settlements' vulnerability to flood risks in African cities: A conceptual framework. Jàmbá J. Disaster Risk Stud. Vol 9 No 12017 (2017) doi:10.4102/jamba.v9i1.370.

47. Mykhnenko, V. \& Turok, I. East European Cities - Patterns of Growth and Decline, 1960-2005. Int. Plan. Stud. 13, 311-342 (2008).

48. Zaninetti, J.-M. \& Colten, C. E. Shrinking New Orleans: Post-Katrina Population Adjustments. Urban Geogr. 33, 675-699 (2012).

49. Qiang, Y., Lam, N. S. N., Cai, H. \& Zou, L. Changes in Exposure to Flood Hazards in the United States. Ann. Am. Assoc. Geogr. 107, 1332-1350 (2017).

50. Birkmann, J. \& Fernando, N. Measuring revealed and emergent vulnerabilities of coastal communities to tsunami in Sri Lanka. Disasters 32, 82-105 (2008).

51. Parape, C. et al. Building Damage and Business Continuity Management in the Event of Natural Hazards: Case Study of the 2004 Tsunami in Sri Lanka. Sustainability 5, 456-477 (2013). 
52. Blum, A. G., Ferraro, P. J., Archfield, S. A. \& Ryberg, K. R. Causal Effect of Impervious Cover on Annual Flood Magnitude for the United States. Geophys. Res. Lett. 47, (2020).

53. Sebastian, A., Gori, A., Blessing, R. B., van der Wiel, K. \& Bass, B. Disentangling the impacts of human and environmental change on catchment response during Hurricane Harvey. Environ. Res. Lett. 14, 124023 (2019).

54. Opach, T., Glaas, E., Hjerpe, M. \& Navarra, C. Vulnerability Visualization to Support Adaptation to Heat and Floods: Towards the EXTRA Interactive Tool in Norrköping, Sweden. 20 (2020).

55. Painter, M. An inconvenient cost: The effects of climate change on municipal bonds. J. Financ. Econ. 135, 468-482 (2020).

\section{Methods}

\section{Flood Event Catalogues}

We used the Dartmouth Flood Observatory (DFO) flood event catalogue as the source for identifying the dates and locations of major flood events. The DFO flood event catalogue provides approximate locations (polygons and points) and date ranges of 4,712 flood events starting in $1985^{1}$ (Extended Data Fig 1A). Other publicly available global flood event catalogues, such as Em-Dat ${ }^{56}$, are other sources of major flood events but have limitations for this study. Em-Dat is globally representative and has three inclusion criteria: 10 or more people killed, 100 or more people affected, or a state of emergency declared. Em-Dat provides location data at the country level, limiting its use in this analysis. For example, many floods cross country borders and mapping very large countries when an event only occurs in a small area can introduce computation challenges and algorithm errors. The DFO includes large media events identified through internet news searches, especially from the FloodList media website, which has been reporting media for major flood events since 2008 (http://floodlist.com/). The DFO database polygon data of estimated flood locations, which Em-Dat does not provide, allows us to filter satellite imagery repositories in focused areas for application of flood detection algorithms.

We compared DFO and Em-Dat both temporally and spatially at the country level to assess differences and bias. The DFO and Em-Dat events were matched over the study period 2000 to 2018 (during the satellite data record) by using country names and overlapping date periods with the fuzzyjoin $\mathrm{R}$ package ${ }^{57}$.

The number of flood events in the DFO from 2000-2018 $(n=3,195)$ is greater than EmDat $(n=3,010)$. The number flood events per year in DFO and Em-Dat is positively and significantly correlated $(0.591$ Pearson correlation, $\mathrm{p}<0.01)$, congruent with results found in another study for years $1985-2019(\mathrm{r}=0.636, \mathrm{p}<.001)^{21}$. DFO reports more floods in years $2000-$ 2009 than Em-Dat (except for 2005), but less than Em-Dat in 2010-2018 (Extended Data Figure 8A). Spatial comparison reveals DFO reports more floods than Em-Dat in the United States (+192 events), Australia (+79 events) and Russia (+31 events). DFO reports less events than EmDat in South America (-36), Central America (-30), the Caribbean (-20), and Africa (-166 across the continent, -94 in West Africa) (Extended Data Figure 8B). The comparison of flood event databases suggest that the DFO event catalogue represents trends in major flood events over time, but may underrepresent floods in Africa and South America.

\section{Satellite Data \& Inundation Detection Algorithm}

\footnotetext{
${ }^{1}$ As of December $31^{\text {st }}, 2018$
} 
For the purposes of historical flood observation, the Moderate Resolution Imaging Spectroradiometer (MODIS) onboard NASA's Terra and Aqua satellites was used due to several advantages among publicly available sensors. MODIS is an optical satellite commonly used for inundated area mapping ${ }^{35,36,58-61}$, is freely available, and has a consistent daily catalogue of images since February 2000 and twice-daily since February 2001. The DFO database contains 3,127 eligible flood events that co-occurred with MODIS imagery (Extended Data Fig 1B).

We used the Google Earth Engine (GEE) platform ${ }^{62}$ to pre-process and apply water detection algorithms to MODIS images. The polygon areas provided with each DFO polygon represents an approximate area impacted by the event, but does not capture the full extent of the flood event. Therefore, we selected all HydroBASINS Level $4{ }^{64}$ watersheds that intersect with the DFO event polygon as our mapping unit (ROI, region of interest) for each event. For each event in the database, we collected and analyzed every MODIS image acquired over the selected watersheds during the event date range provided in the database. As a result, we analyzed 12,719 individual MODIS tiles across the 3,127 events (Extended Data Fig 1).

Terra (MOD09GA/GQ) and Aqua (MYD09GA/GQ) MODIS images used in this study were corrected for atmospheric scattering and absorption to provide estimates of surface reflectance at resolutions of $250-\mathrm{m}$ and $500-\mathrm{m}^{63}$. MODIS data provides reflectance values in the visible $(457-670 \mathrm{~nm})$ and near-infrared $(841-1250 \mathrm{~nm})$ wavelengths at 250-m resolution, while short-wave infrared (1628 - $2155 \mathrm{~nm}$ ) wavelengths which are also commonly used to identify surface water are provided at 500-m resolution. We pan-sharpened the short-wave infrared band to $250 \mathrm{~m}$ with an adapted version of the Corrected Reflectance algorithm ${ }^{64}$ to match the resolution of the other bands.

Inundation extent estimates were produced at 250-m resolution using thresholding approaches based on an algorithm developed by Breckenridge \& Anderson (2006). We produced inundation maps for every event using four versions of the algorithm: 3-day standard, 2-day standard, 3-day Otsu and 2-day Otsu.

The "standard" version of the algorithm identifies water using fixed threshold values on an index referred to as $B 2 B 1_{\text {Ratio }}$ (Equation 1), the SWIR band (Band7/ B7, $1628-1652 \mathrm{~nm}$ ), and removes thick clouds by thresholding the Red band (Band1/ B1, 621-670nm). A pixel is classified as water if $\mathrm{i})$ the $B 2 B 1_{\text {Ratio }}$ is $<0.7\left(K_{1}\right)$, ii) the SWIR band $<675 \mathrm{~nm}\left(K_{2}\right)$, and iii) the Red band is below a reflectance of 2027 ( $C$, Equation 2).

$$
\begin{gathered}
B 2 B 1_{\text {Ratio }}=\frac{N I R+13.5}{\text { red }+1081.1} \\
\text { [Equation 1] } \\
\text { Pixel }_{\text {water }}=\text { Band } 1<C \wedge B 2 B 1_{\text {Ratio }}<K_{1} \wedge \text { Band } 7<K_{2} \quad \text { [Equation 2] }
\end{gathered}
$$

Constants in Equation 1 and 2 were empirically determined $\left(R^{2}=0.91\right)$ by regression discharge data from the US Geological Society (USGS) gauged reaches with MODIS B2B1 ratios ${ }^{58}$.

The "Otsu" version of the algorithm adjusts the thresholds by estimating $K_{l}$ and $K_{2}$ (Equation 2) adaptively for each flood event based on the data acquired for that event ${ }^{43,65}$. Otsu thresholding requires a bimodal distribution, in our case representing spectral reflectance of water and non-water classes, to determine a threshold that minimizes interclass variance (i.e. misclassification). We extracted a sample of 2,500 water and non-water pixels (1,250 sampled for each class) from a median composite of MODIS images for each flood event with clouds removed using the internal cloud state band. Water and non-water pixels for each flood event 
were differentiated by matching the flood event year to the permanent water classification for that year from the Joint Research Center (JRC) Global Surface Water (GSW) Yearly History dataset (Pekel et al. 2016). By choosing MODIS pixels from the permanent water classification in the GSW, we can confidently sample water pixels. From our sample inter-class variance was calculated as the between-sum-of-squares (BSS):

$$
B S S_{T}=\sum_{k=1}^{p}\left(S R_{T, k}-S R_{T}\right)^{2}
$$

[Equation 3]

Where $p$ is equal to the number of classes, $S R$ the mean surface reflectance in band or index $T$ and class $k$. The BSS was calculated iteratively across each bin of a bimodal histogram for both the $B 2 B 1_{\text {Ratio }}$ and the SWIR band. The maximum BSS, and thus the minimized inter-class variance, was selected as a threshold for both the $B 2 B 1_{\text {Ratio }}$ and the $S W I R$ band which was then applied to Equation 1 (Extended Data Fig. 2A-B). Using the flood events that passed the quality control evaluation (see details below), the average optimal threshold for the $B 2 B 1_{\text {Ratio }}$ and $S W I R$ bands were 0.77 and 599, respectively (Extended Data Figure 2C-D). Compared to the standard thresholds $\left(B 2 B 1_{\text {Ratio }}=0.7\right.$ and SWIR $\left.=675\right)$, the Otsu method provides threshold estimates that represent global conditions of water as opposed to available USGS gauge data. While the Otsu method provides each event with scene-optimized thresholds, the fact that the median Otsu thresholds were very close to the standard thresholds confirms that the standard thresholds perform consistently on a global basis.

Equation 1 is used to classify each ROI over the period of a flood event. Following classification of each ROI, using either standard or Otsu versions, multi-day composites are calculated to reduce false detections. Using 3-day composites, a pixel maintains a water classification if over 4 observations out of a possible $6(66 \%)$ were classified as water whereas 2day composites require 2 observations out of $4(50 \%)$. Reducing images to multi-day composites removes misclassifications of cloud shadow, a common misclassification with water ${ }^{66}$, because clouds and their shadows are mobile between image acquisitions. We did not mask clouds with the MODIS 1-kilometer internal cloud state band, as it removed large portions of flooded area detectable under thin or cirrus cloud conditions. To prevent confusion of water with terrain shadows, areas greater than 5-degrees slope were masked out of the final classification using a digital elevation model ${ }^{67}$, as done in other water detection studies ${ }^{35}$.

Permanent water pixels were masked out to isolate only flood waters in excess of permanent water. Inundated pixels are defined as those classified as water following the 3- or 2day compositing and which lie outside of permanent water defined by the Global Surface Water datase $^{34}$. In the Global Surface Water dataset pixels are identified as permanent water when the Landsat observations in both 1985-1999 and 2000-2016 have water presence. After post processing, each flood event has four data products including the 3-day standard, 2-day standard, 3-day Otsu and 2-day Otsu, each of which contain three bands: 1) maximum extent of inundation (flood water $=1$; not flood water $=0$ ) 2) duration of inundation in number of days and 3 ) the percent of cloud and shadow free pixels available across the event.

\section{Evaluation of the Inundation Detection Algorithm}

To assess the accuracy of the Global Flood Database, we identified 123 flood events with Landsat 5, 7, and, 8 imagery at 30m resolution available within 24-hours of the day of maximum inundation and $<20 \%$ cloud cover. Maximum inundation dates were estimated by selecting the 
day (between start and end dates for each event) with the largest inundated area estimated by the algorithm. The 123 resulting flood events used for validation assessment span 15 biomes to assess sensitivity of the algorithm in different landscapes ${ }^{68}$ (Extended Data Fig. 3).

The number of sampling points selected in remote sensing analysis can impact map accuracy ${ }^{69}$. We conducted sensitivity analysis to determine the number of validation points required to minimize the variance in accuracy metrics (precision, recall, and overall accuracy). We sampled 500 points for 10 floods events, stratified as $25 \%$ in permanent water, $50 \%$ in flood water, and $25 \%$ in non-water regions. Points were randomly subsampled, without replacement, to assess accuracy in intervals of 1 from 0 to 500 points (Extended Data Fig. 4A). We found the standard deviation in accuracy fell below 0.1 when 250 or more points where sample, and therefore chose to sample 250 points per flood event for the remainder of the dataset.

Interpretation of validation points was undertaken by a team of trained analysts who identified each point as water, non-water or no data totaling 30,685 validation points. Analysts had access to Landsat images visualized in natural color, false color infrared and two indices that highlight water (Normalized Difference Vegetation Index (NDVI) and Modified Normalized Difference Water Index (MNDWI) ${ }^{70}$ to decide if each pixel was at least $50 \%$ dry or wet. Each validation point was assessed by three separate analysts with the majority vote determining the class of the validation point.

Classification agreement and errors were calculated by comparing per pixel classes from the produced flood maps to the validation data (Supplementary Table 1). Errors of omission and commission $^{61,69}$ were calculated using Equations $4 \& 5$.

$$
\begin{aligned}
& \text { Errors of Omission }=\frac{t p}{t p+f n} \quad[\text { Equation 4] } \\
& \text { Errors of Commission }=\frac{t p}{t p+f p}
\end{aligned}
$$

where $t p$ is the count of true positive pixels, $f n$ is the count of false negative pixels and $f p$ is the count of false positive pixels.

The 3-day standard algorithm performed better than the other 3 algorithms, with an overall accuracy of $83 \% .43 \%$ of floods had accuracies of $>90 \%$ and $65 \%$ of floods had accuracies above $>75 \%$ (Supplementary Table 2). The standard version of the algorithm performed best on average compared to the Otsu thresholds, as the standard threshold results were more consistent. While the Otsu derived thresholds reduced false detections and increased accuracy in some events, other events resulted in overpredicted flood extent (Extended Data Fig. 4B). Errors of omission had no clear geographic pattern while errors of commission were more common at higher latitudes (Extended Data Fig. 5).

\section{Flood Map Quality Control}

To create the final library of flood maps, every map produced underwent a quality control process to eliminate poor quality maps and choose the more accurate map between the two thresholding methods. As the 3-day composite version of the algorithms had higher accuracy than the 2-day composite versions on average, all final maps were chosen from the 3-day composite results (Extended Data Fig. 4C). Each flood map $(n=3195)$ was visually inspected to assess if the map was a suitable representation of flooding. We employed a method similar to the NASA flood detection algorithm quality control procedure ${ }^{71}$. Quality control (hereafter QC) was 
completed by analysts trained to identify several metrics summarized here (see Supplementary Table 3 for a complete list). Analysts recorded if a flood map i) mapped area additional to permanent water (from water masks ${ }^{34,72}$ or Google Earth; ii) was obscured by clouds; iii) which version of the algorithm (standard or Otsu) best matched visible water from MODIS imagery for the maximum inundation date. The analyst determined the product was a useful representation of the flood event if it mapped inundation beyond permanent water and was not largely obscured by clouds (and marked maybe if unsure). Analysts viewed the DFO polygon, all original MODIS imagery for the flood event, watersheds intersected by the flood, the standard flood map, the Otsu flood map, underlying high resolution satellite imagery from Google Earth, and a hyetograph of the $95 \%$ percentile of precipitation in the DFO polygon as estimated by the PERSIANN satellite ${ }^{73}$ to make QC decisions.

279 flood events were assessed by at least two separate analysts to calculate intercoder reliability. Analysts agreed on classifying the flood event as "useful representation of the flood event" (see Supplementary Table 3, Question 3) for 203 events, representing 73\% intercoder reliability. Flood events marked as "maybe" or where analysts disagreed were quality checked by the first author of this paper to make final decisions.

Some floods of low quality may be present in the database that should not have passed QC, and local knowledge of any area should be leveraged when using these global data. We encourage users to pair our convenient online catalog of events and flood dates with the MODIS worldview tool (https://worldview.earthdata.nasa.gov/) to visually examine if additional flood extent could be mapped by downloading individual MODIS images where water is present in only 1-2 observations and therefore lost in the 3-day composites. Caution is advised, however, when mapping inundation with only 1-2 images as cloud shadow is could misclassified as water. The supplementary data include the QC information for each flood event. Extended Data Fig. 6 shows the results of the QC assessment across the globe.

QC results yield 913 flood maps determined to be useful representations of flooding (29.4\% of the all DFO events that were mapped). Maps employing Otsu thresholding for 124 flood extents $(13.5 \%)$ were shown to better capture flood extent as compared to standard threshold maps. The final Global Flood Database produced by this study thus includes 789 maps using the standard threshold, and 124 maps using event-specific Otsu thresholds.

A large proportion of flood events from the DFO database (2,212 events, $43.1 \%$ of events mapped) did not reveal areas of widespread flooding and failed quality control. The top three reasons noted for failing QC included extreme cloud cover, $(n=495,16 \%$ of events), no standing water beyond existing permanent water ( $n=300,10 \%$ of events), and unmapped floods in urban areas ( $n=44,1.5 \%$ of events). MODIS may fail to capture i) rapid, flash flood events, ii) small channels of water below 250 resolution (e.g. flooded streets in urban areas), and iii) inundation below dense canopy cover. The algorithm employed here is based on an optical sensor, requiring clear view of an inundated pixel for a minimum of 4 MODIS acquisitions over 3 days and therefore will not detect fast moving floods. Urban floods are challenging to map given small features such as canals or roads cannot be resolved at $250-\mathrm{m}$ resolution 27,74 . Floods in heavily forested areas with dense canopy are also underrepresented in our database. Finally, incorrect event start and end dates from the event catalogue could influence flood event map quality if they are not inclusive of maximum inundation.

\section{Estimating Observed Flood Exposure, Recent Past}


A previous study examined flood exposure trends with the relative exposure change ratio $^{75}$, which measures the ratio of population exposed to observed floods from 2000 to 2015 versus total population change in this same period, calculated with Equation 6.

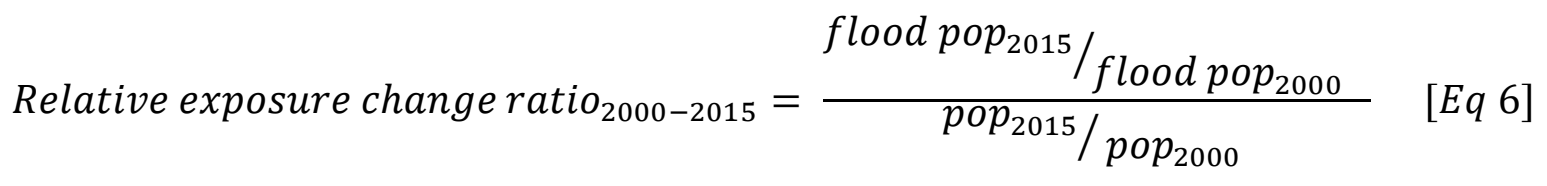

We rearrange these terms to generate a more intuitive metric, the change in proportion of population exposed to floods between 2000 and 2015 (Equation 7). If the change in the proportion of the population exposed (from eq. 7 ) to floods equals 1.35 , this is equivalent to a $35 \%$ increase in the proportion of the population exposed to floods. A metric of 1 (e.g. no change) occurs when total population and flood exposed population increase at the same rate.

$$
\text { change in proportion of flood exposed pop } p_{2000-2015}=\frac{\text { flood } p o p_{2015} / p_{\text {op }} 2015}{\text { flood } p o p_{2000} / p_{000}} \quad \text { [Eq.7] }
$$

To estimate global flood exposed population (flood pop), we calculated maximum inundated area across the Global Flood Database between 2000 and 2018 by masking areas that never flooded, and setting all pixel values to 1 if it was inundated at least once. This observed inundated area was intersected with the Global Human Settlement Layer (GHSL) for years 2000 and 2015 to calculate population in the flood exposed area. GHSL was selected due to its global availability, matching resolution of MODIS (250m pixels), and better accuracy compared to other globally available population data ${ }^{76}$. Due to the potential noise of scattered singular flood pixels, especially along coastlines which contained mixed pixels at the ocean-land interface, we removed isolated pixels (not connected to at least two other pixels) for area and population calculations. This reduced the population exposure count globally by approximately 20 million people, but did not change the results of the comparison to global flood models or trends.

Flood pop was estimated per country by summing populations residing in the observed floodplain for years 2000 and 2015. Countries with a ratio of flood maps to total known flood events from the DFO catalogue $<0.13$ (the $50^{\text {th }}$ percentile across all countries) were marked as having insufficient data ( $n=86$ countries; Extended Data Fig 6C). A total of 120 countries were used in this analysis once countries with insufficient data were removed. Estimates of population inundated in at least one observed flood event from 2000-2018 are significantly correlated to flood exposure estimates for the 100-year return period hazard area from a flood model, GLOFRIS $^{19}(\mathrm{r}=0.89, \mathrm{p}<0.001$, Pearson's correlation, Extended Data Fig 10). These results suggest the distribution of flood exposed population observed by the Global Flood Database are congruent with results from a flood model, and the data can be used for comparing past and future trends.

\section{Estimating Observed Flood Exposure, Near Term Future}

Estimates of population exposed to future floods is taken from the WRI Aqueduct Flood Risk Analyzer ${ }^{45}$. These data are from the output of the GLOFRIS flood model, which uses an average of 5 climate model outputs coupled to a hydrologic and hydraulic model. We used the $8.5 \mathrm{RCP}$ 
climate model results and the 100-year flood zone, congruent with other flood exposure studies $^{14,75,77,78}$, and the SSP2 socioeconomic pathways scenario (which predicts future growth will follow historical patterns ${ }^{40}$ ). The change in proportion of population at flood risk is expressed in Equation 8.

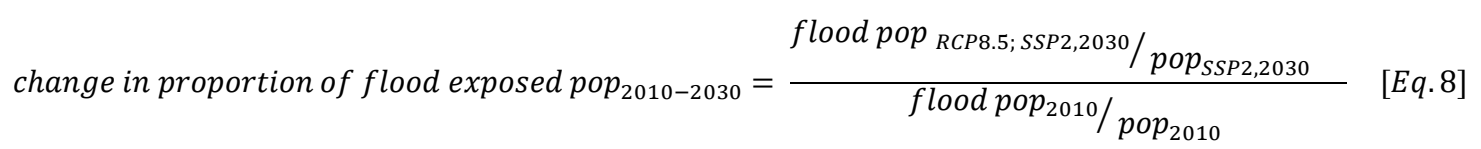

\section{Sensitivity analysis of return periods and population exposure changes 2010-2030}

While previous studies analyzed flood exposure trends of 100-year return periods ${ }^{14,75,78}$, we also examined the sensitivity of results to different return periods reported by Aqueduct (500, $250,100,25$, and 10). The total number of people exposed to floods from 2030 as compared to 2010 increases as the return period increases (Extended Data Fig. 7A), with Asia accounting for the highest population increases. When analyzing the percent change from 2030 as compared to 2010, however, the percent increase for flood exposure assessed for each region across return periods is similar (Extended Data Fig. 7B). The only continent with changes in trends of population exposure that differ by return period is Europe, where there is an expected 5\% increase in the proportion of population exposed to floods in the 10 -year return period, but a $10 \%$ increase in the 250- and 500-year return periods. While Africa has the highest percentage increase in flood exposed population, it also has the highest total population increase, with a mean of $47 \%$ (Extended Data Fig. 7C), suggesting the increase in flood exposure is due to population growth. In Asia, however, while the total population percentage increase is $25 \%$ on average, the percent change in flood exposed population is on average over $30 \%$. As a result, after normalizing for population growth, Asia has the highest increase in the proportion of population exposed to floods across all return periods (Extended Data Fig. 7D). Extended Data Fig. 7D shows the change in proportion of flood exposed population is not sensitive to return periods (except for potentially Europe), indicating the choice of return period does not influence country and continent level trends in changes in the proportion of population exposed to floods.

\section{References}

57. Em-Dat The international Disaster Database. (Centre for Research on the Epidemiology of Disasters - CRED).

58. Robinson, D., Bryan, J. \& Elias, J. fuzzyjoin. (2020).

59. Brakenridge, R. \& Anderson, E. MODIS-based flood detection, mapping and measurement: The potential for operational hydrological applications. in Transboundary floods: reducing risks through flood management 1-12 (Springer, 2006).

60. Sakamoto, T. et al. Detecting temporal changes in the extent of annual flooding within the Cambodia and the Vietnamese Mekong Delta from MODIS time-series imagery. Remote Sens. Environ. 109, 295-313 (2007).

61. Islam, A. S., Bala, S. K. \& Haque, A. Flood inundation map of Bangladesh using Modis surface reflectance data. in International conference on water and flood management (ICWFM) Dhaka, Bangladesh vol. 2 739-748 (Citeseer, 2009).

62. Boschetti, M., Nutini, F., Manfron, G., Brivio, P. A. \& Nelson, A. Comparative Analysis of Normalised Difference Spectral Indices Derived from MODIS for Detecting Surface Water in Flooded Rice Cropping Systems. PLoS ONE 9, e88741 (2014). 
63. Gorelick, N. et al. Google Earth Engine: Planetary-scale geospatial analysis for everyone. Remote Sens. Environ. 202, 18-27 (2017).

64. Lehner, B. \& Grill, G. Global river hydrography and network routing: baseline data and new approaches to study the world's large river systems: GLOBAL RIVER HYDROGRAPHY AND NETWORK ROUTING. Hydrol. Process. 27, 2171-2186 (2013).

65. Vermote, E. \& Saleous, N. LEDAPS surface reflectance product description. Coll. Park Univ. Md. Dep. Geogr. (2007).

66. Gumley, L., Descloitres, J. \& Schmaltz, J. Creating reprojected true color MODIS images: A tutorial. Univ. Wisconsin-Madison 19, (2010).

67. Donchyts, G., Schellekens, J., Winsemius, H., Eisemann, E. \& van de Giesen, N. A 30 m Resolution Surface Water Mask Including Estimation of Positional and Thematic Differences Using Landsat 8, SRTM and OpenStreetMap: A Case Study in the Murray-Darling Basin, Australia. Remote Sens. 8, 386 (2016).

68. Verpoorter, C., Kutser, T. \& Tranvik, L. Automated mapping of water bodies using Landsat multispectral data: Automated mapping of water bodies. Limnol. Oceanogr. Methods 10, 1037-1050 (2012).

69. Danielson, J. J. \& Gesch, D. B. Global multi-resolution terrain elevation data 2010 (GMTED2010). (2011).

70. Dinerstein, E. et al. An Ecoregion-Based Approach to Protecting Half the Terrestrial Realm. BioScience 67, 534-545 (2017).

71. Congalton, R. G. A review of assessing the accuracy of classifications of remotely sensed data. Remote Sens. Environ. 37, 35-46 (1991).

72. $\mathrm{Xu}, \mathrm{H}$. Modification of normalised difference water index (NDWI) to enhance open water features in remotely sensed imagery. Int. J. Remote Sens. 27, 3025-3033 (2006).

73. Nigro, J., Slayback, D., Policelli, F. \& Brakenridge, G. R. NASA/ DFO MODIS Near Real-Time (NRT) Global Flood Mapping Product Evaluation of Flood and Permanent Water Detection. 27.

74. Carroll, M. L., Townshend, J. R., DiMiceli, C. M., Noojipady, P. \& Sohlberg, R. A. A new global raster water mask at $250 \mathrm{~m}$ resolution. Int. J. Digit. Earth 2, 291-308 (2009).

75. Ashouri, H. et al. PERSIANN-CDR: Daily Precipitation Climate Data Record from Multisatellite Observations for Hydrological and Climate Studies. Bull. Am. Meteorol. Soc. 96, 69-83 (2015).

76. Schumann, G., Brakenridge, G., Kettner, A., Kashif, R. \& Niebuhr, E. Assisting Flood Disaster Response with Earth Observation Data and Products: A Critical Assessment. Remote Sens. 10, 1230 (2018).

77. Jongman, B., Ward, P. J. \& Aerts, J. C. J. H. Global exposure to river and coastal flooding : Long term trends and changes. Glob. Environ. Change 22, 823-835 (2012).

78. Pesaresi, M. et al. Operating procedure for the production of the Global Human Settlement Layer from Landsat data of the epochs 1975, 1990, 2000, and 2014. (2016).

79. Irvine, P. J., Sriver, R. L. \& Keller, K. Tension between reducing sea-level rise and global warming through solar-radiation management. Nat. Clim. Change 2, 97-100 (2012).

80. Tanoue, M., Hirabayashi, Y. \& Ikeuchi, H. Global-scale river flood vulnerability in the last 50 years. Sci. Rep. 6, (2016).

\section{Data Availability}

Individual flood events $(n=913)$ from the Global Flood Database can be visualized and downloaded by event and country here: $\mathrm{http}$ ://global-flood-database.cloudtostreet.info/, as well as summary statistics of all events.

\section{Code Availability}

Google Earth Engine's web interface allows the flood mapping algorithm defined in equations 1 and 2 to be applied on any MODIS images. Access will be available upon request. 


\section{Acknowledgement}

Thanks to students at the University of Washington for quality checking and validating the GFD database: Simon Lau, Chi Chi Wu, Putri Khalilah Kamaluddin, William Pietsch, Sarah Lau, Gyobeom Jason Kim, Henry Tran and John Crinkey. Thanks to students from University of Texas at Austin, including Clarice Norton. Thanks for the Cloud to Street staff who quality checked additional portions of the database, Sam Weber and Emmalina Glinskis. Thanks to B.L. Turner II, Upmanu Lall, Venkat Lakshmi, and Peter Kareiva who provided comments on this manuscript. Funding for this project was provided by a Google Earth Engine Research Award.

\section{Author Contributions}

B.T conceived the study, led population exposure analysis, writing, and project administration. J.A.S conceived the study and algorithm, designed the validation, led data curation, and contributed to writing and editing. C. K. led algorithm accuracy and validation analysis and quality control. C.S.D contributed to algorithm development, data visualization, and curation. A.J.K. contributed to quality control, writing, and editing. G.R.B. contributed to editing and data curation of the event database. T. E contributed to data curation. D.A.S contributed to quality control.

\section{Competing interests}

Two of the authors (Beth Tellman and Colin Doyle) are employed by and hold stock in a company, Cloud to Street that sells flood observation and satellite monitoring technology. The data in this paper are free and open, and the company expects no direct financial benefit from this study.

\section{Additional Information}

Supplementary Tables are provided with these data, and all data can be downloaded from http://global-flood-database.cloudtostreet.info/. 


\section{Extended Data Figures}

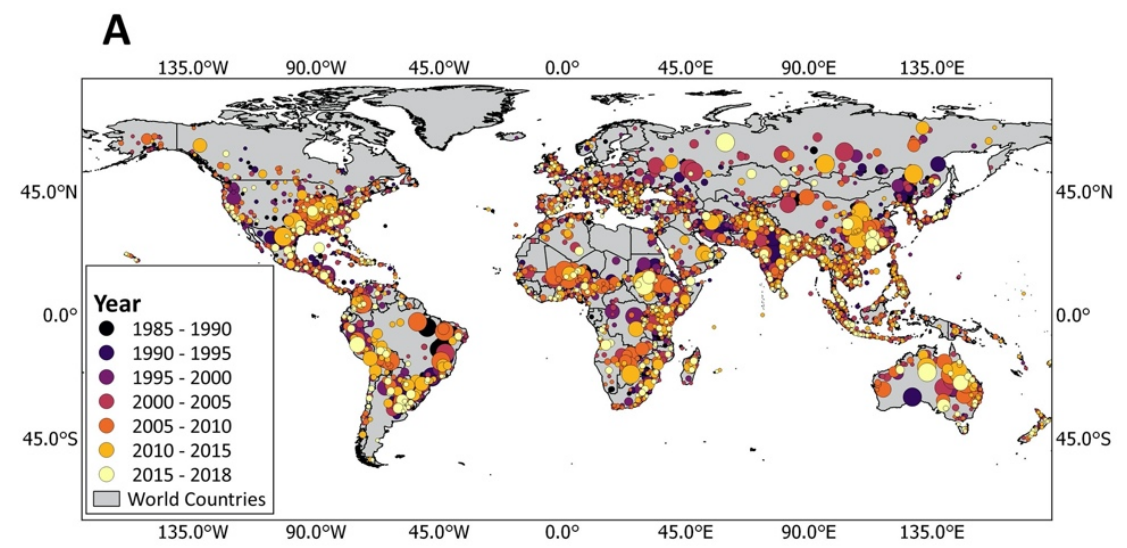

B

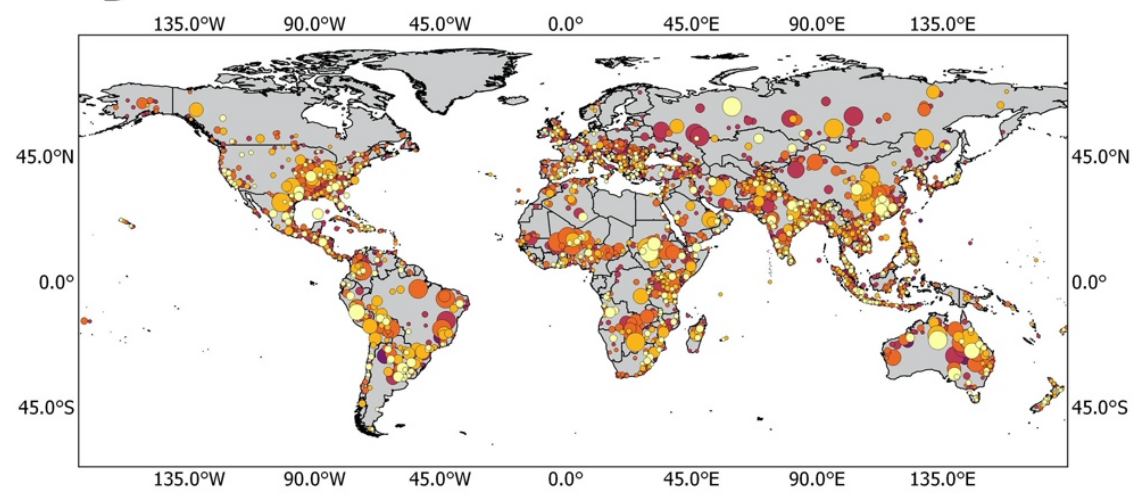

C

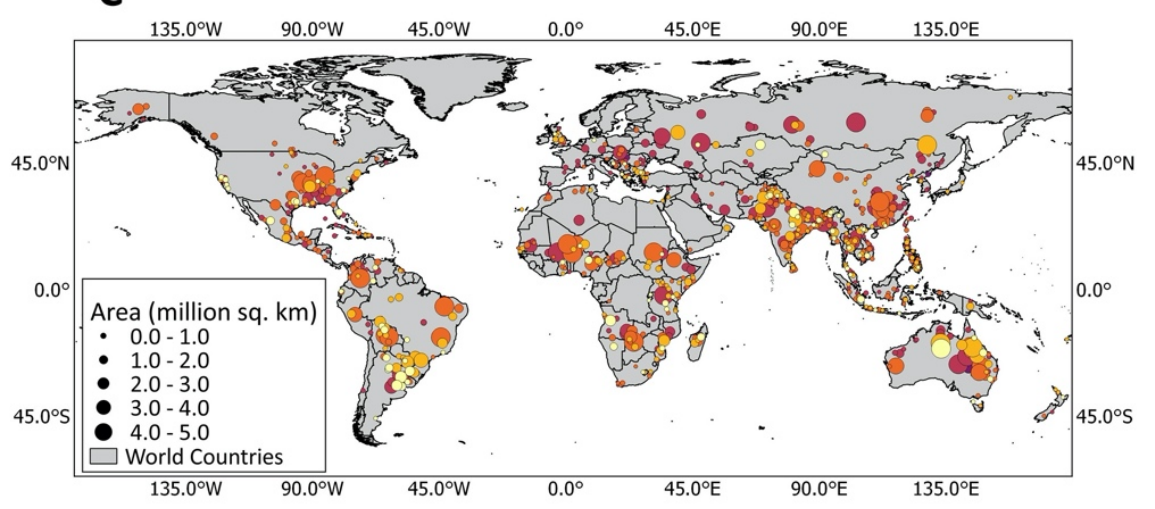

Extended Data Fig. 1 | Global distribution of flood events catalogued by the Dartmouth Flood Observatory and the Global Flood Database. Flood events (A) in the DFO starting from January 1st, 1985 to December 31st, $2018(n=4,712)$, (B) in the DFO and coincident with MODIS imagery $(n=3,127)$ and $(\mathbf{C})$ that passed the Quality Control evaluation for the Global Flood Database $(\mathrm{n}=913)$. 

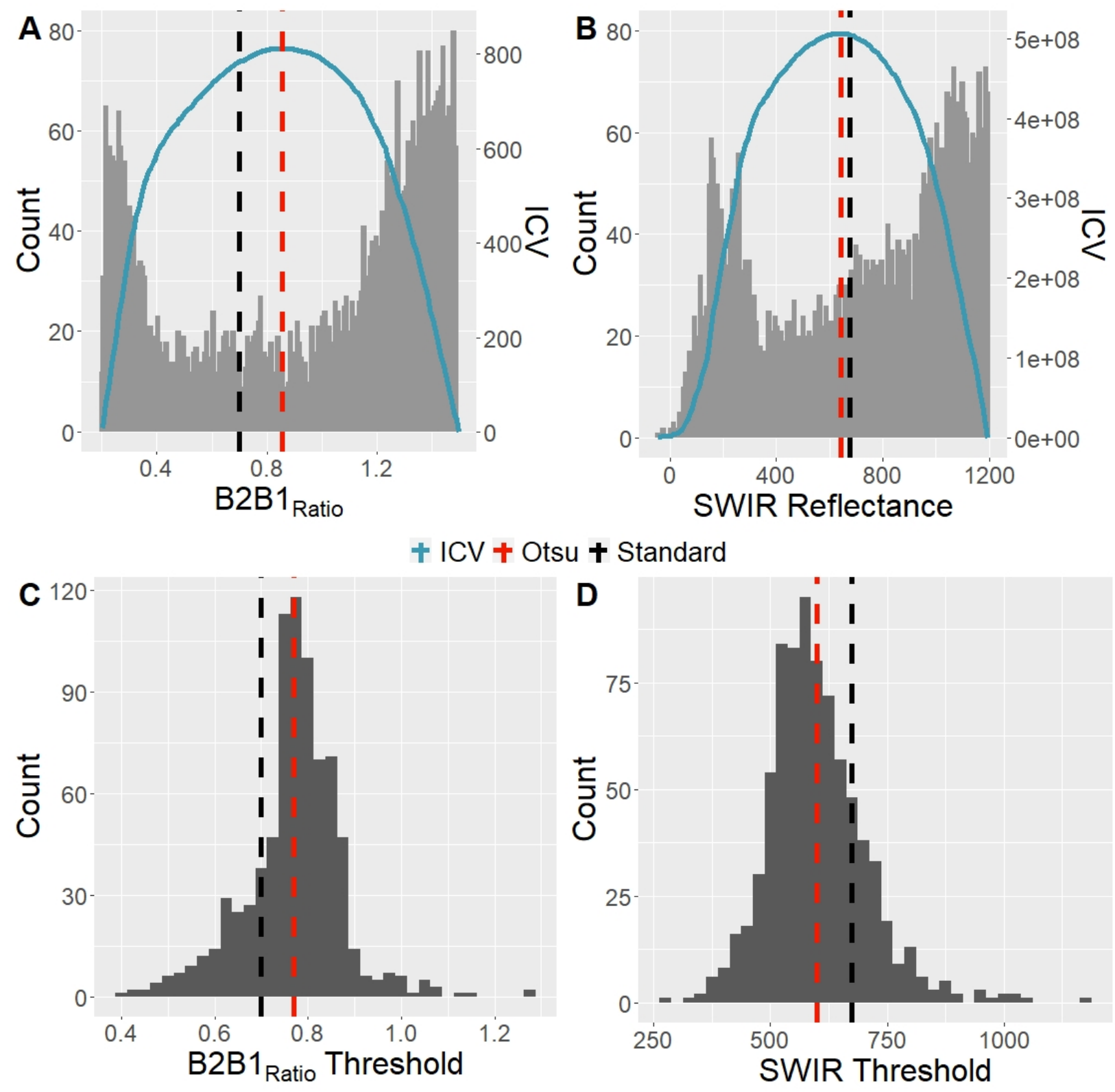

I Otsu I Standard

Extended Data Fig. 2 | Example of bimodal histograms used to calculate adaptive thresholds for water classifications that approximate, on average, the standard versions of water classification thresholds. A-B, Example bimodal histograms with ICV (interclass variance) extracted from MODIS imagery for a flood event in Argentina in November 2003 (DFO Flood ID 2381) used to determine optimal thresholds for (A) B2B1 Ratio and (B) SWIR band. C-D, Otsu thresholds are calculated for each flood event in the Global Flood Database $(\mathrm{n}=913)$ for the (C) $B 2 B 1_{\text {Ratio }}$ and (D) SWIR bands. The average Otsu threshold for $B 2 B 1_{\text {Ratio }}$ (0.77) and SWIR (599) are comparable to the standard thresholds for B2B1 Ratio $(0.70)$ and SWIR (675). 


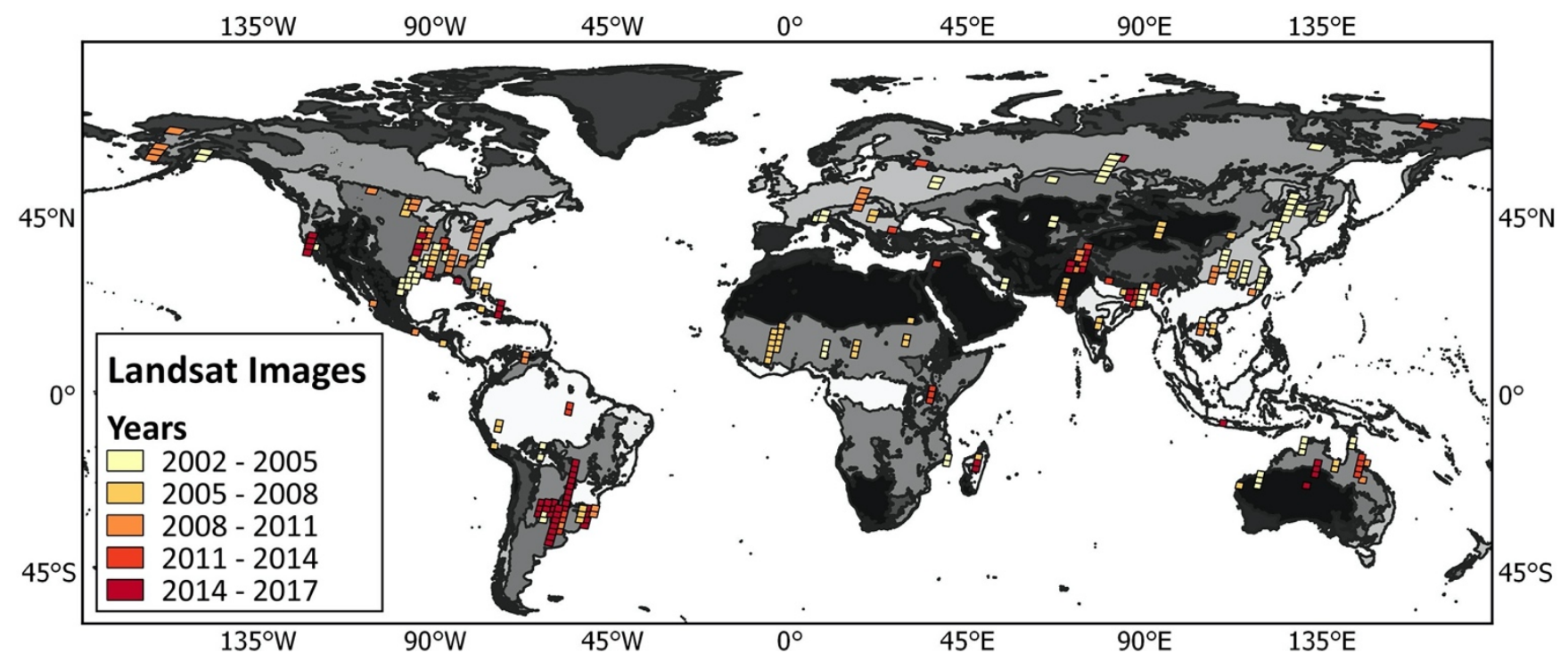

Extended Data Fig. 3 Selected Landsat 5, 7 and 8 imagery for the evaluation of 123 flood events in the Global Flood Database are globally distributed, cover 15 biomes and span 15years. Flood events for validation were selected based on availability of Landsat imagery. Availability of imagery included conditions that Landsat imagery occurred within 24-hours of the maximum extent day of a flood, intersected the flood area and had less than $20 \%$ cloud cover. Landsat tiles overlaid a biomes map from Dinerstein et al. $2017^{68}$. 

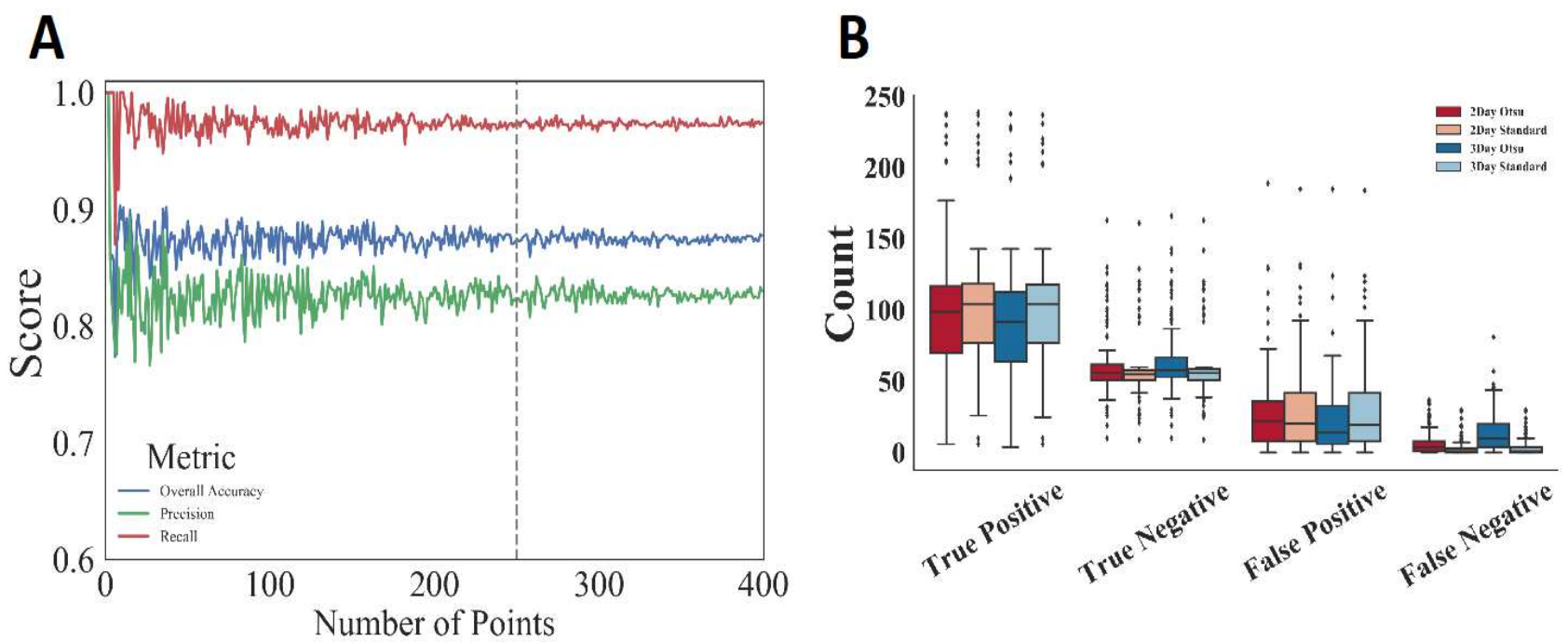

\begin{tabular}{lllllll}
\hline Method & Window & $\begin{array}{l}\text { Overall } \\
\text { Accuracy }\end{array}$ & Commission & Omission & Precision & Recall \\
\hline Otsu & 2 days & 0.82 & 0.23 & 0.08 & 0.77 & 0.92 \\
Standard & 2 days & 0.82 & 0.23 & 0.03 & 0.77 & 0.97 \\
Otsu & 3 day & 0.80 & 0.21 & 0.15 & 0.79 & 0.85 \\
Standard & 3 days & 0.83 & 0.23 & 0.04 & 0.77 & 0.96
\end{tabular}

Extended Data Fig. 4 | Global Flood Database accuracy metrics. (A) Sensitivity plot of accuracy metrics with random sampling of 500 points for 10 flood events. (B) Error analysis showing the distribution of true positive (tp), true negative (tn), false positive (fp) and false negative (fn) rates for each of the four methods and (C) accuracy statistics summarized by each thresholding method and image composite choice (metrics per event in Supplementary Table 2). 


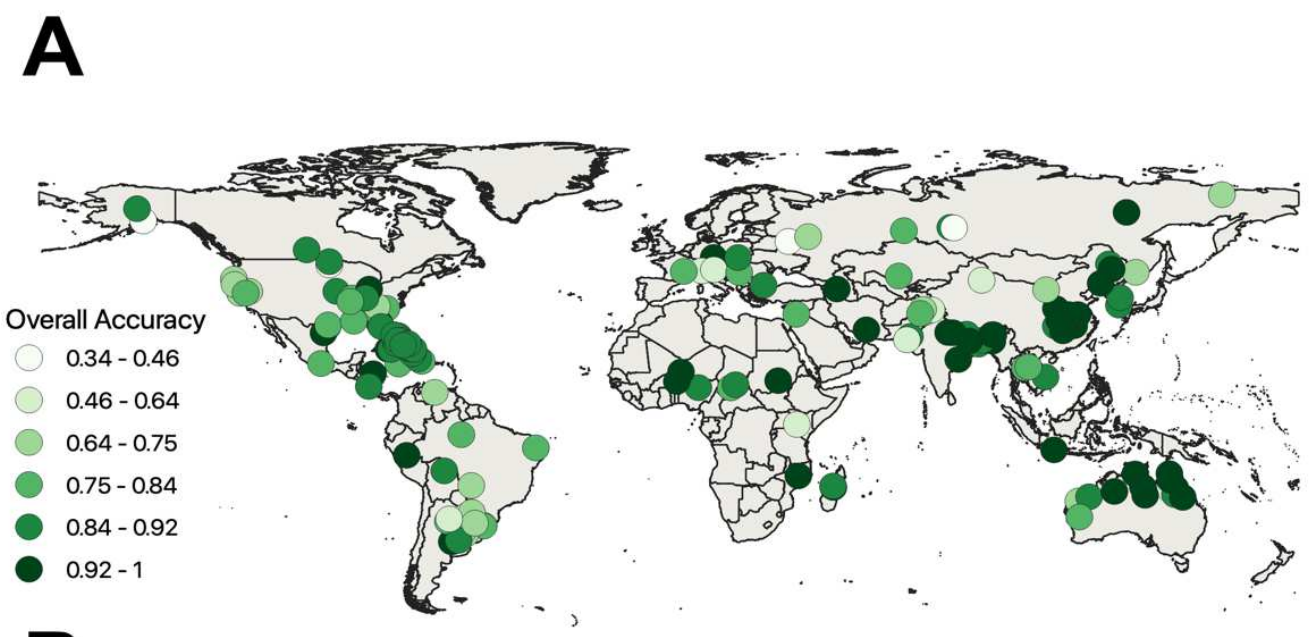

B
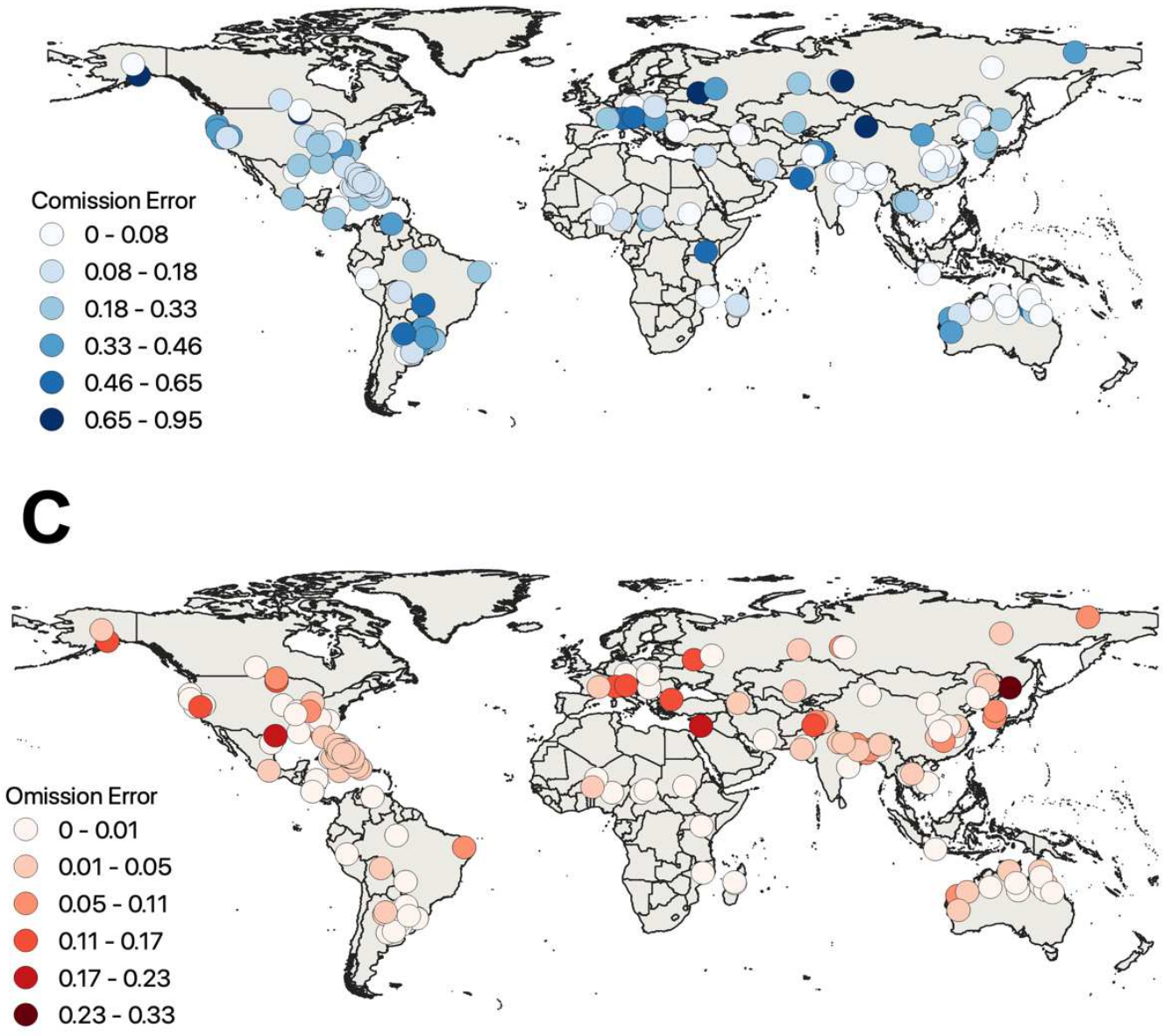

Extended Data Fig. 5 | Global distribution of accuracy metrics based on 123 flood events from the Global Flood Database. (A) Overall accuracy is consistently distributed across the globe while (B) errors of commission are inflated at higher latitudes and (C) errors of omission are lower than errors of commission and have no clear spatial pattern. 

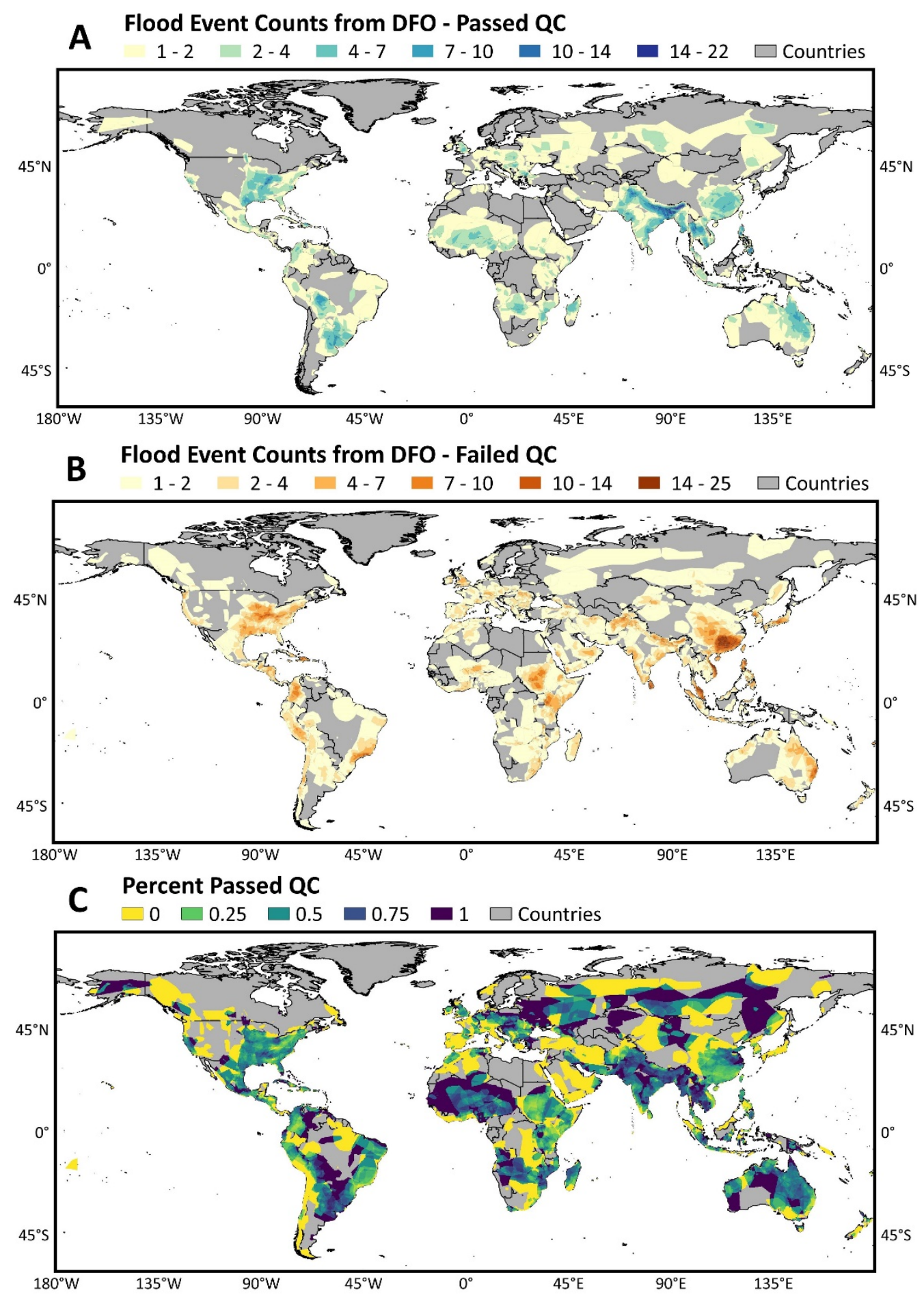

Extended Data Fig. 6 | Results of the Quality Control assessment show coverage of the Global Flood Database is well represented in Southeastern United States, Central America, South America, Southeast Asia, Australia, West Africa and East Africa. A-C, Counts of flood events that (A) passed quality control or (B) failed quality control and (C) the percent of events that passed as a ratio of total flood events. 

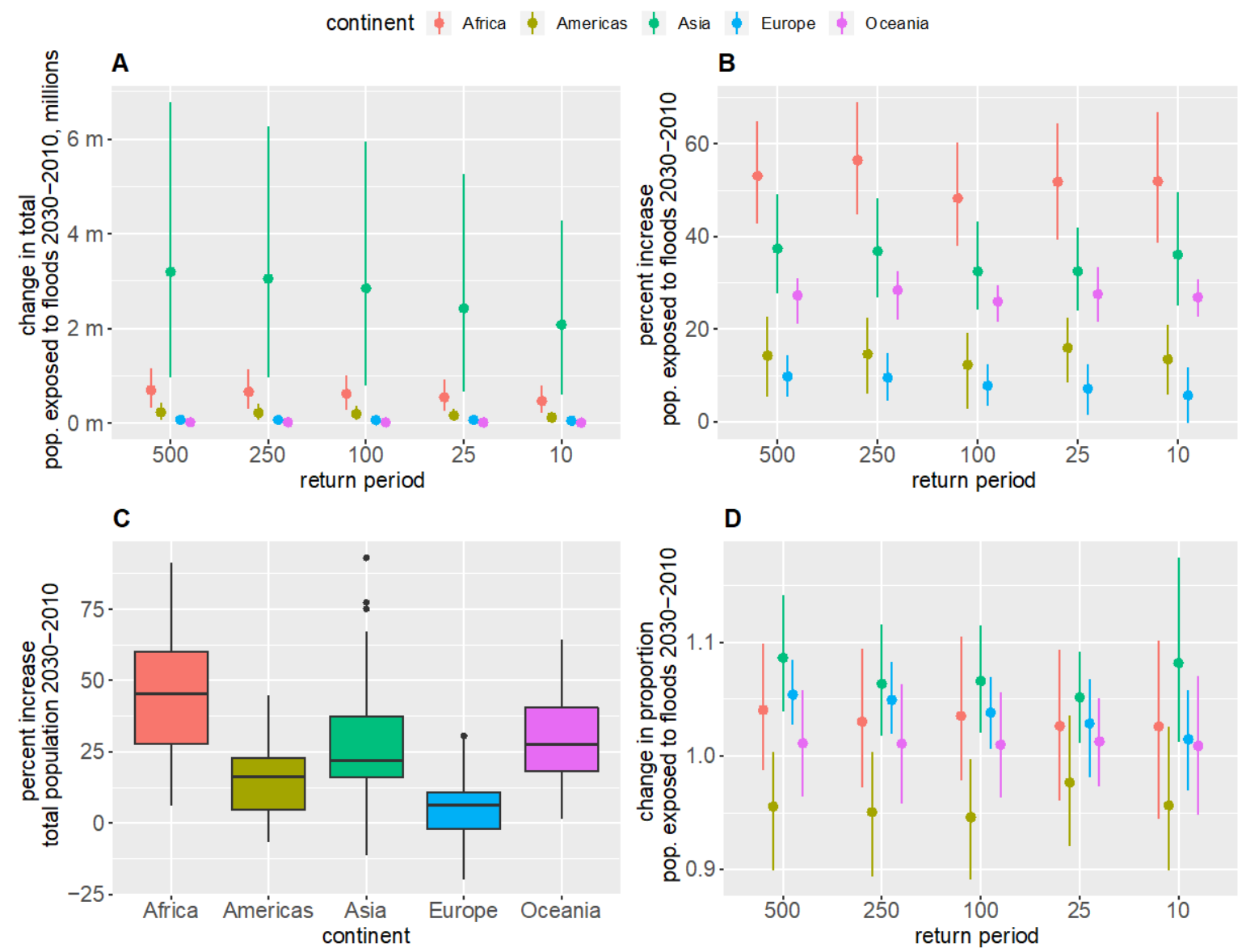

Extended Data Fig. 7 | Sensitivity analysis of return periods to flood exposure changes

2010-2030. (A) Mean change in total population (in millions) exposed to floods from 2030-2010, per return period, summarized by continent, with 2 standard errors in bars; (B) percent increase of population exposed to floods 2030-2010, per return period; (C) percent increase of total population 2030-2010 per continent; (D) mean change in proportion of population exposed to floods, with 2 standard errors in bars. 

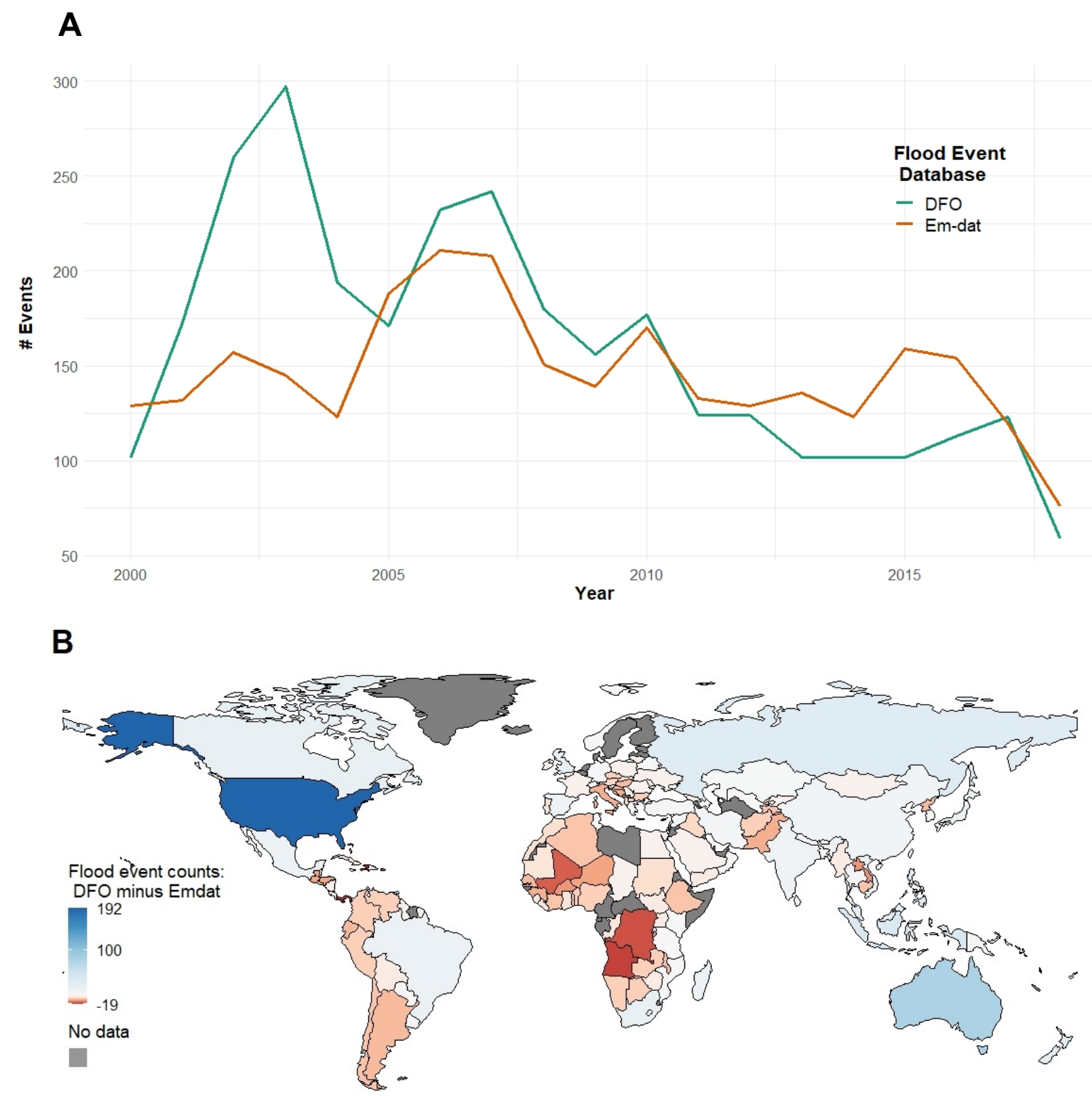

Extended Data Fig. 8 | Comparison of the Dartmouth Flood Observatory and Em-dat flood events databases shows moderate correlation temporally, greater representation of events by DFO in USA, Australia and Russia and a smaller catalogue of events by DFO in Africa and Latin America than Em-dat. (A) Annual flood events in Dartmouth Flood Observatory and Em-dat. (B) Flood events in Dartmouth Flood Observatory minus flood events in Em-dat summarized by country. 


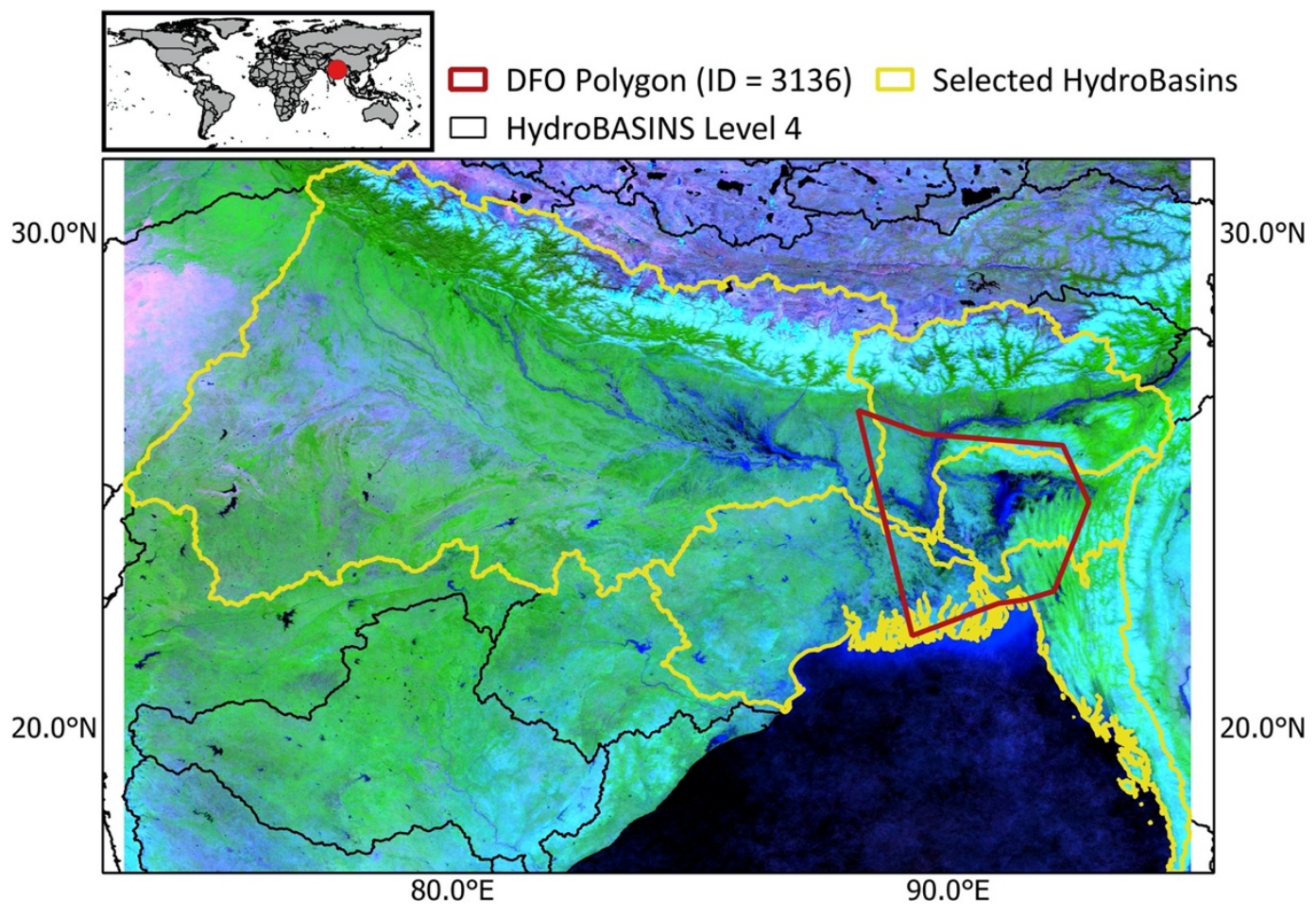

Extended Data Fig. 9 | Example selection of satellite imagery for a flood event in Bangladesh in 2007 using HydroBASINs and Dartmouth Flood Observatory Polygon (DFO Polygon). Background image is a median composite of MODIS imagery visualized as RGB-721 (SWIR, NIR, Red) during the flooding period July 21, 2007 to October 15, 2007. 


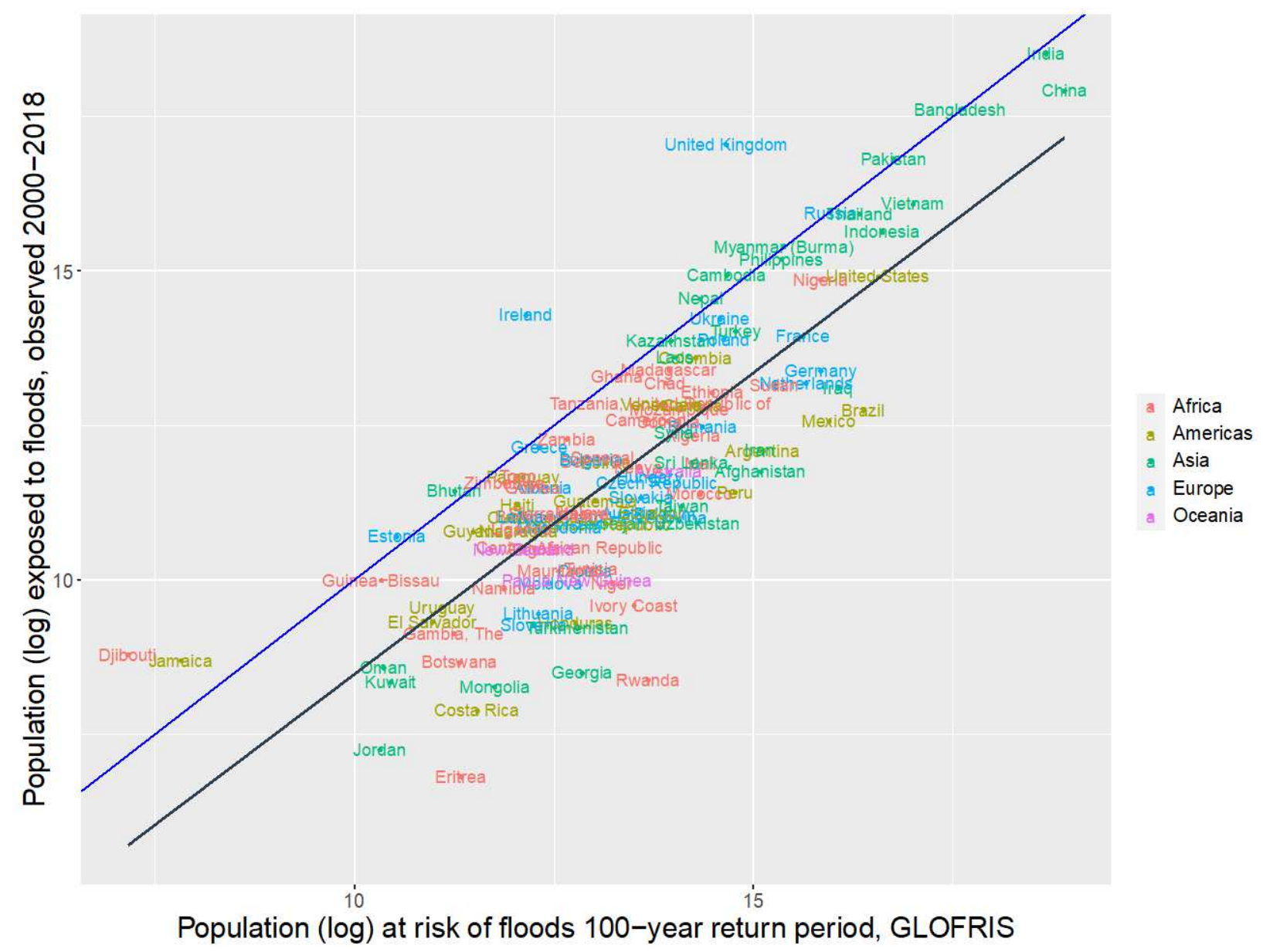

Extended Data Fig 10. Per country comparison of populations exposed to floods in a 100year event (using 2010 climate and population) from GLOFRIS versus estimates of total population exposed from the Global Flood Database, 2000-2018. Pearson's correlation, $\mathrm{R}=0.89, \mathrm{p}<0.001$. The blue line represents the $1-1$ line, and black line the linear regression line, countries colored by continent. 


\section{Figures}
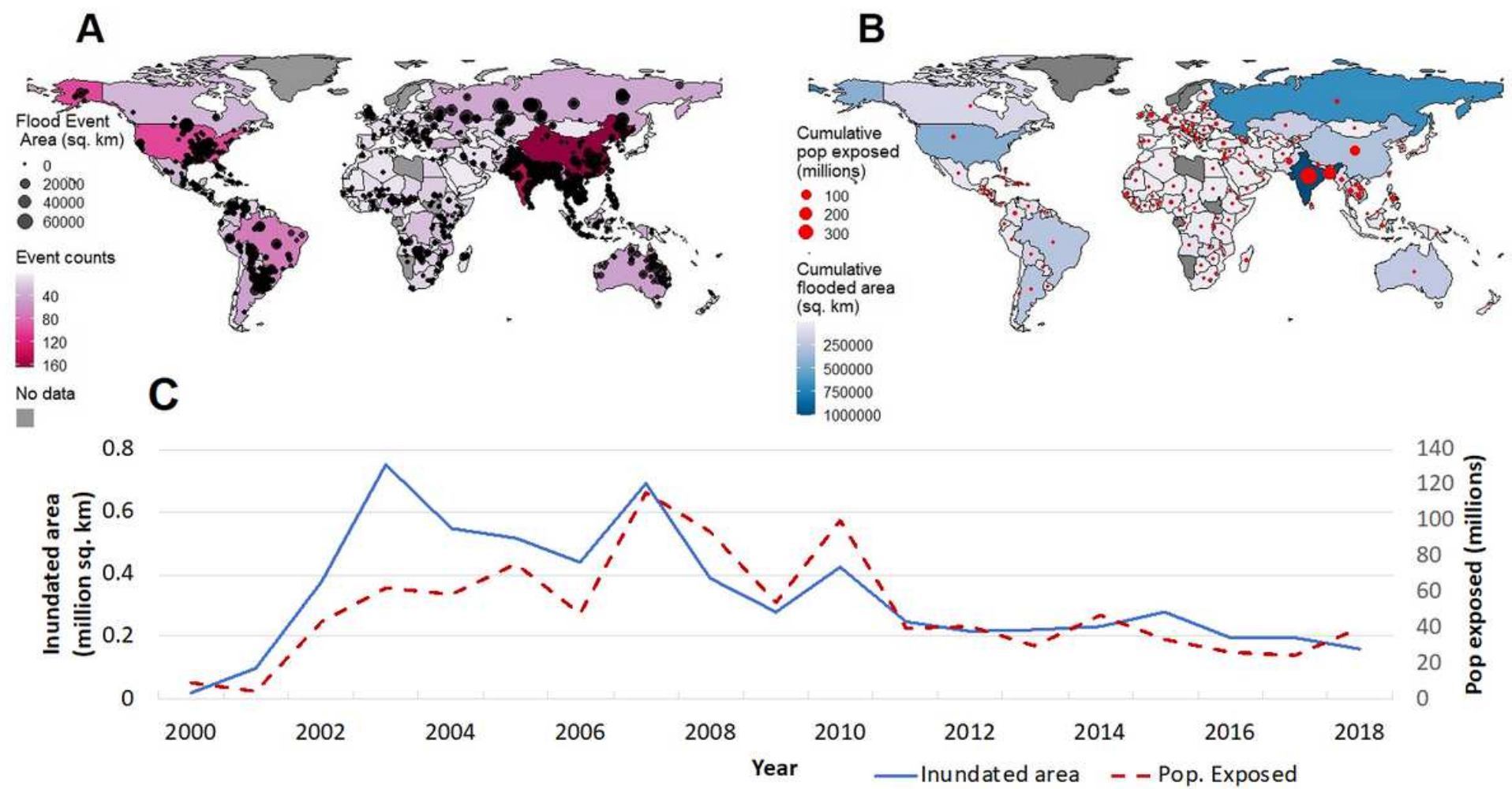

Figure 1

Summary Statistics of the Global Flood Database. A) Number of events in the Global Flood Database per country, with centroid locations marked in black B) Map of total exposed population and exposed area (per country, Supplementary Table 6) and C) Annual global population and area inundated. The 913 flood events only represent those for which high quality data was available (see quality control section, methods). Population and area exposure to floods are lower in 2000 and 2001 until a second satellite (Aqua) was launched with a MODIS sensor on board, allowing for twice daily global coverage and increasing the probability of mapping a flood event from 5\% in 2000 to $30 \%$ in 2002 and afterwards. Note: The designations employed and the presentation of the material on this map do not imply the expression of any opinion whatsoever on the part of Research Square concerning the legal status of any country, territory, city or area or of its authorities, or concerning the delimitation of its frontiers or boundaries. This map has been provided by the authors. 


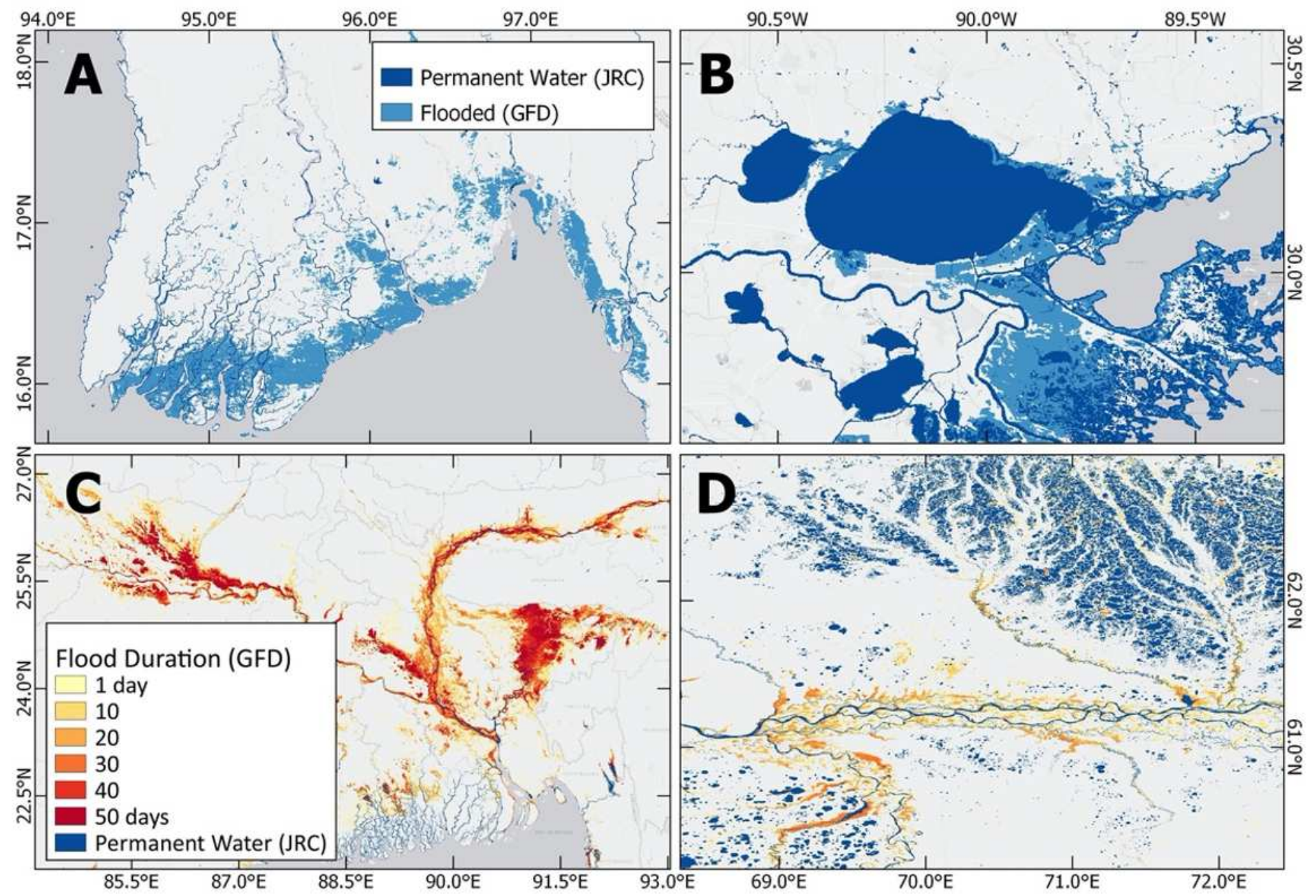

Figure 2

Observed inundation in the Global Flood Database versus permanent water (from the Joint Research Program (JRC), see Pekel et al 2016) (A-B) and flood duration versus permanent water (C-D) for selected extreme flood events of the Global Flood Database. A) The highest mortality; 100,000 people due to Cyclone Nargis, Burma, 2008. B) The most expensive event; Hurricane Katrina, 60 billion USD, 2005. C) The highest estimated exposure, 27 million people, exposed to the 2004 floods in India and Bangladesh. D) The largest flood (98,000 km2), observed in Russia, 2003. (Basemap: Bing Maps). 

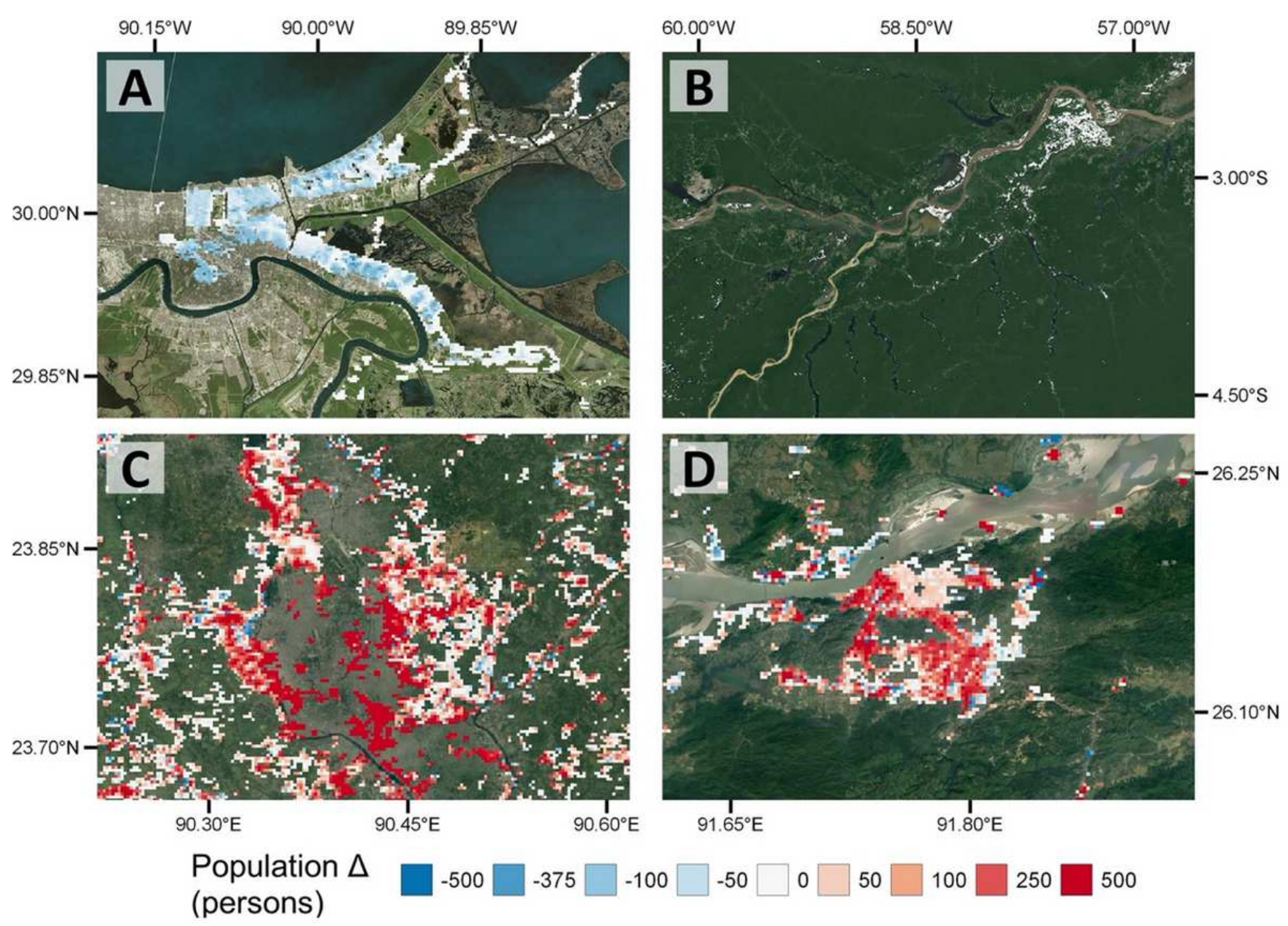

\section{Figure 3}

Population dynamics per pixel $(250 \mathrm{~m})$ in observed inundated areas, 2000-2018. A) New Orleans, Louisiana, loses population after Hurricane Katrina (Basemap: Bing Maps). B) Manaus, Brazil, no population change C) Dhaka, Bangladesh, increasing population in inundated areas in the peri-urban zone. D) Guwahati, Assam, India, an urbanizing town on the Brahmaputra River repeatedly exposed to flooding over the past two decades. (Basemap B-D: Google Maps) 


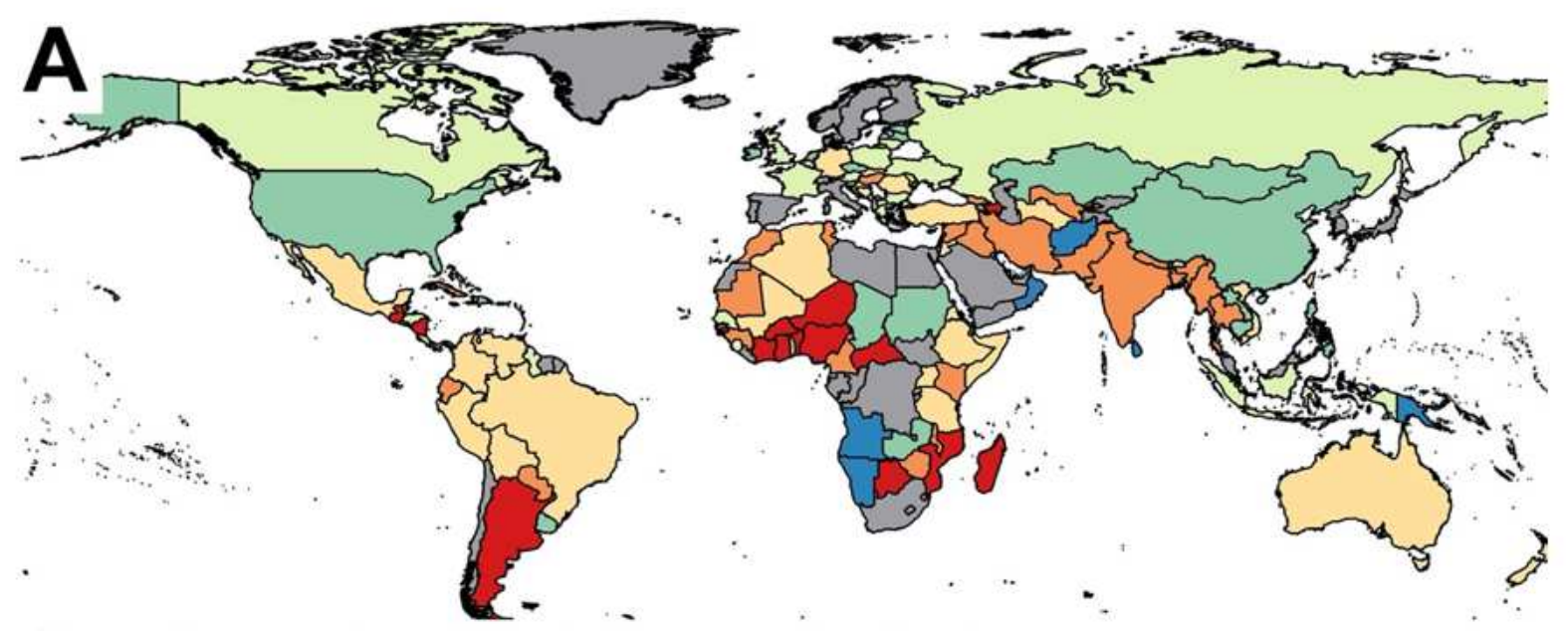

Change in proportion of population exposed to floods

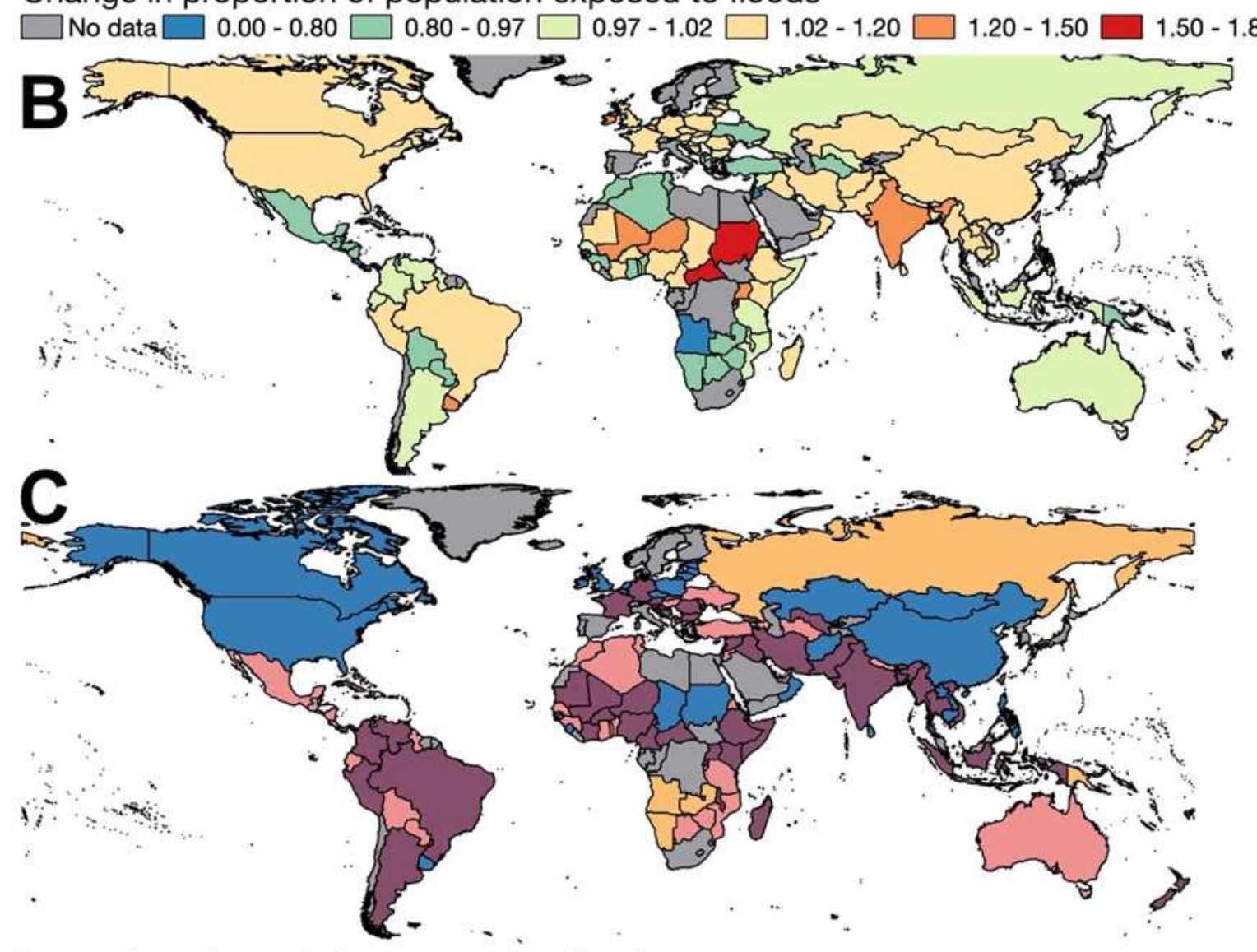

Proportion of population exposed to floods

Decreasing in past \& future $\square$ Insufficient data Increasing in future (2010-2030) Increasing in past \& future Increased in past (2000-2015)

\section{Figure 4}

Change in proportion of population exposed to floods observed from satellites and predicted for 2030 from a flood model. (A) Change in proportion of population exposed to floods in observed inundated areas per country, 2000-2015 (B) Change in proportion of flood-exposed population relative to rates of total population change per country, 2010-2030. Color breaks match classification from Jongman et al. (2012) to facilitate comparison. C) Countries where the proportion of population exposed to large floods 
grew (2000-2015) (>1, pink), is expected to grow (2010-2030) (>1, blue), has increased in both the past and future (purple), and remains constant or is decreasing (orange). Grey countries had insufficient flood observations.Note: The designations employed and the presentation of the material on this map do not imply the expression of any opinion whatsoever on the part of Research Square concerning the legal status of any country, territory, city or area or of its authorities, or concerning the delimitation of its frontiers or boundaries. This map has been provided by the authors.

\section{Supplementary Files}

This is a list of supplementary files associated with this preprint. Click to download.

- SupplementaryInformation.zip

- SupplementaryTable6.xlsx 